\title{
La consolidación de la paz en el derecho internacional
}

\section{Peacebuilding in international law}

\author{
M. Cecilia Añaños*
}

\section{Resumen}

La consolidación de la paz (peacebuilding) constituye una de las tareas centrales de las Naciones Unidas en el mantenimiento de la paz y está destinada a reforzar la estatalidad de Estados en situaciones de postconflicto. Cuenta con un determinado marco teórico, descansa sobre una base jurídica determinada y comprende acciones complejas que se han desarrollado a partir de una larga práctica de la organización en el manejo de conflictos. Como objeto de estudio, ha sido tratada abundantemente y perfilada por otras ciencias sociales, no así por el derecho internacional. Este trabajo pretende superar esta deficiencia y contribuir al debate al respecto. Para ello, centrara la atención en el concepto, su desarrollo en la práctica y su base legal, incluyendo los límites jurídicos así como los problemas jurídicos conexos. Se excluyen las cuestiones relacionadas con su practicabilidad, necesidad y fundamentación teórica, así como el análisis de la práctica realizada.

Palabras clave: Consolidación de la paz, Naciones Unidas, construcción del Estado, Estados fallidos, Estados frágiles.

Licenciada en derecho, docente en diversas instituciones académicas de Alemania. <ceciliaan@web.de> 


\section{Abstract}

Peacebuilding is one of the most important UN activities in peace maintainance, and is aimed at reinforcing statehood in countries after conflict. It has a theoretical framework, relies on a legal basis and comprises complex actions in conflict management developed through UN practice over the last decades. As a matter of analysis, it has been extensively appraised and improved by other social sciences, but not by international law. This paper intends to overcome this shortcoming and encourage the relevant debate. It will deal with the concept of peacebuilding, its development and legal status, including its legal limitations and related legal problems. The paper does not cover cuestions of feasibility and necessity, as well as of theoretical foundation and analysis of cases.

KEY WORDS: peacebuilding, United Nations, State building, failed States, weak States.

Recibido el 20 de septiembre de 2010; aceptado el 14 de enero de 2011. 
M. Cecilia AÑaños • La consolidación de la paz...

\section{INTRODUCCIÓN}

No cabe duda que el sistema internacional -sustrato material del derecho internacional- ha sufrido transformaciones con la caída del bloque soviético, en el sentido de que existe un orden unipolar que ha acelerado el progreso global del capitalismo, la democracia y la militarización de la política internacional. Los acontecimientos del 11/9 hicieron aún más notoria esta estructura de desbalance del poder ${ }^{1}$, que en el plano político y jurídico condujeron a defender la existencia de nuevas condiciones políticas mundiales sustanciales, y por tanto, a justificar nuevas reglas de derecho internacional que se distancian de las existentes en 1945, forjando con ello el surgimiento de un «derecho mundial» apoyado en conceptos globalizadores como «orden global del Estado moderno» o «gobernanza mundial», que ya habían hecho su aparición a comienzos de los años noventa del siglo XX.

1 La referencia al factor «poder» que es determinante en las decisiones políticas internacionales y por tanto relevante para el derecho internacional, no obvia la creciente interdependencia simétrica y asimétrica de los Estados debido al proceso de globalización. El fin de la Guerra Fría tampoco significa el surgimiento de una nueva estructura del sistema internacional sino tan solo el ajuste o desplazamiento del poder en un solo Estado y en sus élites sin traer cambios cualitativos en el ordenamiento jurídico internacional. En este sentido vid. Simpson, G., Great Powers and Outlaw States. Unequal Sovereigns in the International Legal Order, Cambridge University Press, Cambridge 2004, p. ix s.
A raíz de estas tendencias globalizadoras en las esferas de la política y el derecho, se anunció precipitadamente la pérdida de importancia del Estado en el sistema internacional. En realidad este, sigue siendo el actor principal en un orden iusinternacional de carácter estatal u «orden westfaliano» de estructura coordinada entre Estados soberanos, basado en la igualdad soberana y la diversidad política, aun con las considerables limitaciones a la soberanía estatal producto del crecimiento de la normatividad internacional. La Organización de las Naciones Unidas, surgida de un orden político postbélico en 1945, se creó a partir de este orden de Estados soberanos, pero a la vez ha sido un actor dinámico en la configuración de este orden político y su adecuación a las nuevas tendencias de la política internacional, de ahí que se pueda aceptar -con limitaciones- el supuesto de que existen actualmente dos estructuras de ordenamiento internacional con dos modelos diferentes: el westfáliano y el de las Naciones Unidas ${ }^{2}$.

Las Naciones Unidas, altamente susceptible a los cambios de la política mundial, ha realizado a partir de los años noventa numerosas modificaciones para adecuarse a las nuevas tendencias universalizadoras, sobre todo en un componente relevante como el de la seguridad colectiva. Modificaciones que se deben principalmente a su rol más activo en el mantenimiento de la paz, cuyo balance arroja resultados tanto

2 Krieger, H., (2000), p. 30ss. 
positivos como negativos. Mientras no ha podido evitar el estallido de numerosos conflictos armados - predominantemente situados en el Tercer Mundo-y guerras asimétricas como las de Kosovo, Afganistán e Irak, sus actuaciones en el encauzamiento de los conflictos armados y en la ayuda humanitaria en países azotados por conflictos armados o catástrofes naturales, son en general positivamente valoradas.

La consolidación de la paz (peacebuilding) es un producto de los cambios más relevantes operados en el sistema de las Naciones Unidas en los últimos veinte años. Mediante ella, la organización asume la tarea de fortalecer o reforzar al Estado y así evitar o impedir su desintegración o debilitamiento. No sin razón este tipo de empresa ha sido denominada «despotismo benevolente» o «autocracia benevolente» ${ }^{3}$, y en este contexto puede considerarse como un organismo internacional de gestión de conflictos» ${ }^{4}$. Para conocer en qué consiste la consolidación de la paz como tarea actual y futura de las Naciones

3 Beauvais, J., «Benevolent Despotism: A Critique of U.N. State-Building in East Timor", New York University Journal of International Law and Politics, vol. 33 (2003), 1101-1178; Chesterman, S., You, the People. The United Nations, Transitional Administration and State-Building, Oxford U.P., Nueva York 2004, p. vii, 8.

4 Debiel, T., «Konfliktbearbeitung in Zeiten des Staatsverfalls: Erfahrungen und Lehren zu Beginn des 21. Jahrhunderts", Blanke, U. (Ed.), Krisen und Konflikte. Von der Prävention zur Friedenskonsolidierung, Berliner Wissenschafts-Verlag, Berlin 2004, 21-38, p. 24.
Unidas, se hace necesario ocuparnos primero del concepto de «construcción del Estado» o «state-building».

\section{Aspectos CONCEPTUALES}

\section{La construcción del Estado}

\section{(state-building)}

La consolidación de la paz (peacebuilding) se relaciona con las expresiones «construcción del Estado» (statebuilding) o "construcción de nación» (nation-building $)^{5}$, que son prácticas internacionales que se han desarrollado de forma considerable en los últimos años y en el último tiempo tratadas por el derecho internacional.

Se entiende por "construcción del Estado» la actividad orientada a reponer la estatalidad o rehabilitar estructuras de administración y gobierno, siguiendo determinados modelos de construcción, como la democracia liberal y la economía de mercado, y valores como el respeto del Estado de derecho (rule of law), los derechos humanos y la integración social y política de la población. La misma corre a cargo de entes extranjeros, que son Estados, grupos de Estados u organizacions internacionales y procede en casos de desintegración

Tanto «construcción del Estado» como «construcción de la nación» se usan indistintamente para designar lo mismo. Ambos términos no son fácilmente diferenciables, aunque el primero se enfocaría en la construcción de instituciones estatales y el segundo subrayaría el factor «nación» como objeto de la construcción. 
M. Cecilia AÑaños • La consolidación de la paz...

de estructuras internas de un Estado (Estados fallidos) o de estatalidad defectuosa ${ }^{6}$ (Estados frágiles), resultantes de un conflicto armado interno o mixto, de una intervención militar extranjera exitosa seguida de ocupación, o de una operación de establecimiento de la paz (peace enforcement action) de las Naciones Unidas. Se trata pues de una empresa extremadamente compleja que incluye actos de la más diversa índole, como la ayuda o apoyo humanitario a la población, tareas de administración y gobierno y medidas de desarrollo. La historia contemporánea conoce ejemplos exitosos de "construcción del Estado» en Alemania y Japón por las potencias vencedoras de la II Guerra Mundial, y otros más recientes pero menos o nada exitosos como en Somalia, Kosovo, Afganistán e Irak.

Por considerarse como una de las formas más intrusivas de intervención ${ }^{7}$, la "construcción del Estado», que está

6 Epping, V., (2007) «Völkerrechtliche Aspekte defektiver Staatlichkeit», Epping, V./ Heintze, H.-J. (Eds.), Wiederherstellung staatlicher Strukturen in Nach-KonfliktSituationen. Bochumer Schriften zur Friedenssicherung und zum humanitären Völkerrecht 55, Berliner WissenschaftsVerlag, p. 9.

7 «Nation-building is perhaps the most intrusive form of foreign intervention there is. It is the massive foreign regulation of the policy-making of another country. The process usually entails the replacement or, in the case of a country in a state of anarchy, the creation of governmental institutions and a domestic political leadership that are more to the liking of the power or powers conducting the intervention.» Dempsey, G., «Fool's errands: America's recent encoun- respaldada por doctrinas liberales de la gobernanza mundial, provenientes en su mayoría del ámbito anglosajón ${ }^{8}$, tiene un carácter bastante controvertido en el ámbito de las relaciones internacionales, y sobre todo en el derecho internacional ${ }^{9}$. Junto con el fin de fortalecer los Estados se encuentra la intención de remodelar o transformar sus estructuras internas mediante modelos políticos de Estados democráticos occidentales, con lo cual se afecta la esfera de su soberanía interna y el derecho de autodeterminación de los pueblos. Esto exige una justificación, por lo menos jurídica, dentro del derecho internacional positivo, tema que no se tratará directamente en esta oportunidad. Sin embargo, nos detendremos ahora en el objeto de la intervención de los «Estados fallidos» o frágiles, que consituyen

ters with nation-building», Mediterranean Quarterly 12 (1), 2001, 56-80, p. 59.

8 Entre sus defensores están: Fukuyama, F. (2004), Dobbins, J. (2003). Para el plano operativo vid. también National Security Research Division (RAND), Beginners Guide to Nation Building, http://www.rand. org/pubs/monographs/2007/RAND_MG557. pdf. (2.2.2010).

9 Desde posiciones escépticas como la de Etzioni, A. (2004), hasta posiciones abiertamente críticas como las de Korhonen, O. (2009), "The 'state-building enterprise': Legal doctrine, progress narratives and managerial governance», Bowden, B. et al.(eds.), The Role of International Law in Rebuilding Societies after Conflict. Great Expectations, Cambridge University Press, 15-7; Bhuta, N. (2009), Bowden, B. et al. (Eds.), op.cit., 38-63; Danchin, P. (2009), Bowden, B. et al. (eds.), op. cit. 64-89; Anghie, A., (2006), 739-753; Oeter, S. (2008), 99 44-60. 
a la vez, uno de los argumentos más fuertes de esta práctica internacional.

a) Los Estados «fallidos» O «frágiles»

Los llamados Estados «fallidos » $\mathrm{y}$ «frágiles» ${ }^{10}$ vienen a ser el objeto central de la «construcción del Estado» por actores extranjeros. Ya que la «fragilidad» se encuentra en relación gradual respecto de los «Estados fallidos», ahondaremos solo en estos últimos por constituir un caso extremo de estatalidad deficiente con relevancia jurídica.

La expresión «Estados fallidos» surge con fuerza a comienzos de la década de los años noventa en círculos políticos y académicos occidentales a raíz de los conflictos existentes en ese entonces en la ex-Yugoslavia, Somalia, Liberia, Sierra Leona y Rwanda, y sirve para referirse a un nuevo desafío y riesgo, producto del fin de la Guerra Fría ${ }^{11}$.

10 Dentro de los Estados frágiles existirían también diferencias de grado entre «Estados que fracasan" ( «failing states «), que se encuentran en peligro de caer pero conservan un mínimo de autoridad estatal y orden político; «Estados durmientes» (sleeping states), que siguen existiendo en virtud de una ficción; y Estados con «estatalidad frágil» («state weakness»), que están en peligro o corren el riesgo de colapsar.

11 Así Thürer, D. (1996), y Herdegen, M. (1996), ambos en: Referate und Thesen von Thürer/Herdegen/Hohloch, Der Wegfall effektiver Staatsgewalt: "The Failed State»Berichte der Deutschen Gesellschaft für Völkerrecht 34, Heidelberg C.F. Müller Verlag; Hufnagel, F.-E. (1996), pp 237 s.; Büttner, A. (2004), Staatszerfall als neues Phänomen der internationalen Politik: Theoretische Kategorisierung und empirische Überprüfung, Marburg, Tec-
Por «Estado fallido» se entiende, pues el colapso de instituciones estatales o la pérdida total o parcial de control del gobierno en Estados que han sido abatidos por un conflicto armado, guerra civil o que han sido objeto de una intervención militar extranjera. En este caso el Estado está imposibilitado de cumplir con sus funciones básicas de legislar, administrar y preservar el orden y la cohesión social. La referencia a este fenómeno, supuestamente nuevo, se basa principalmente en el argumento de que la ausencia de la ley y el orden en un Estado acarrearían consecuencias serias para la estabilidad y la paz mundial ${ }^{12}$, dando a la "comunidad in-

tum; Münkler, H., Viejas y nuevas guerras: asimetría y privatización de la violencia, Madrid, Siglo XXI (2005). Siguiendo estas tendencias vid. Pastor Palomar, A., L. Caflish, y otros (2005) (eds.), El derecho internacional: normas, hechos y valores. Liber Amicorum J. A. Pastor Ridruejo, Madrid, Servicio Publicaciones Facultad de Derecho, Universidad Complutense de, Madrid. Para el tratamiento de la temática vid. Pozo Serrano, P. (2002), pp 173185; Fernández Ruiz G., E. (2009).

12 El impacto desestabilizador en Estados vecinos, el hecho de ser generador de mayor violencia, conflictos violentos internos, de estructuras terroristas, de crímenes organizados y economía ilegal, de violaciones masivas de derechos humanos, del peligro de catástrofe humanitaria, de proliferación de armas, etc., hechos que representarían una "amenaza a la seguridad». Vid. "US National Security Strategy», Washington 17.09.2002, p. 1, accesible en: http:/www.bits.de/NRANEU/others/ strategy/nss02.pdf (4.11.2008); vid. también «Una Europa Segura en un Mundo Mejor» Estrategia Europea de Seguridad, Bruselas 12.12.2003, p. 4 s., accesible en: 
ternacional» una razón para intervenir en ellos. Aparte de ques el concepto de «Estados fallidos» es impreciso para determinar cuando cae o colapsa un Estado, trae consigo controversias al apreciarlo como fenómeno nuevo, producto del fin de la Guerra Fría, y supone que constituye una amenaza a la paz y la seguridad internacional.

En el derecho internacional existe una tendencia a considerar la figura «Estados fallidos» como una nueva forma de extinción de un Estado. Para conocer cuándo un Estado deja de existir como tal, un buen número de autores recurren a la teoría de los 3 elementos de Jellinek: poder estatal, pueblo y territorio. De acuerdo con ella, un Estado se extingue cuando pierde de forma duradera ${ }^{13}$ y completa uno de sus tres elementos. Los «Estados fallidos», debido a la ausencia o desintegración del poder estatal ${ }^{14}$ serían causa de

http://www.consilium.europa.eu/uedocs/ cmsUpload/031208ESSIIES.pdf (4.11.2008).

13 Vid. Murswiek, D. (1996), Referate und Thesen von Thürer/Herdegen/Hohloch, Der Wegfall effektiver Staatsgewalt: The Failed State», Berichte der Deutschen Gesellschaft für Völkerrecht 34, Heidelberg, C.F. Müller Verlag, p. 149. Cfr. Heilbronner, K., en Graf Vitzthum, W. (2004), para quien la pérdida completa y duradera de los elementos territorio y pueblo es decisiva en la extinción de un Estado.

14 Poder estatal entendido como la capacidad de organizar un orden dentro del territorio (soberanía interna) y actuar de forma autónoma y jurídicamente independiente de otros Estados y dentro del marco del derecho internacional (soberanía externa), Epping, op. cit. (n. 6), p. 10 s. extinción del Estado y por tanto, de la extinción de su personalidad jurídica. Sin embargo, la tesis no aclara cuál es el criterio decisivo para determinar la existencia de un «Estado fallido» quién lo determina; también es controvertida por ser la figura de «Estados fallidos» en sí problemática y por no corresponder a la institución jurídica de extinción del Estado. Si el requisito de esta es la pérdida durarera y completa de uno de sus elementos esenciales, entonces los llamados «Estados fallidos» no cumplen con esta exigencia puesto que el poder estatal, de perderse totalmente, es renovable, y su pérdida es siempre temporal. Por lo general estos Estados enfrentan dentro de su territorio conflictos armados, que son luchas políticas por el poder y solo es cuestión de tiempo para que sea nuevamente ocupado por alguna de las partes del conflicto o por un tercero.

El paradigma de los «Estados fallidos» también es respaldado por la tesis de la ficción o la de Estados con carácter ficticio ${ }^{15}$ de acuerdo con la cual la pérdida del poder estatal trae consigo la incapacidad de subsistir del Estado y su desaparación real como tal, aunque sigue existiendo gracias a una ficción jurídica. Esta argumentación llevaría a que existirían dos categorías de Estados: reales y ficticios, "fantasmas» o «zombis», y es igualmente rebatible, pues la sola pérdida del poder estatal

15 De acogida en el ámbito jurídico alemán. Entre sus representantes: Murswiek, D., (1996), pp. 31 ss.; Thürer, (1996), p. 11, 16 ss.; Herdegen, (1996), p. 49 ss. 
no genera automáticamente la desaparición real del Estado cuando siguen existiendo los otros dos elementos, territorio y pueblo, siendo precisamente este el que posee voluntad política y es factor generador y renovador del poder estatal.

En términos de dogmática iusinternacional, la falta de poder estatal de un Estado significa que ha perdido su capacidad de hecho mas no de derecho -como titular de derechos y obligaciones iusinternacionales-, la que sigue conservando aun imposibilitado de ejercer funciones soberanas. Así pues, la falta del poder estatal no toca la personalidad iusinternacional del Estado, este sigue sujeto de derecho internacional en virtud de los principios de continuidad, seguridad jurídica y previsibilidad de las relaciones internacionales. Consecuentemente, los «Estados fallidos» gozan de todos los derechos que tienen otros Estados en virtud del principio de la igualdad soberana. Un trato diferenciador perjudicial a estos sería discriminatorio y afectaría este derecho fundamental. Ellos están protegidos también por la prohibición del uso de la fuerza, siendo ilegal una intervención militar en estos Estados por el mero hecho de ser considerados como «Estados fallidos». Estas aseveraciones se confirman por la práctica del Consejo de Seguridad, cuyas resoluciones no hacen alusión a «Estados fallidos» como amenaza a la seguridad y la paz mundial per se, ni autorizan a intervenir por este motivo, aun en el caso típico de Somalia. La intervención en «Esta- dos fallidos» solo puede ser legal bajo el cap. VII de la Carta $^{16}$ y por razones humanitarias o violaciones graves y sistemáticas de derechos humanos de carácter desestabilizador para la región. Por el contrario, los llamados «Estados fallidos» necesitarían una protección especial más reforzada del derecho internacional para resguardarlos de incursiones o intervenciones extranjeras que reduzcan aún más su soberanía.

\section{La consolidación de la paz («peacebuilding»)}

A diferencia del concepto de "construcción del Estado», que es genérico en cuanto a los actores que aplican las medidas, el de consolidación de la paz (peacebuilding) es propio de las Naciones Unidas ${ }^{17}$, y es la resultante de una larga práctica de esta organización en el mantenimiento de la paz. Dispone de un marco teórico y de una base jurídica determinados y comprende acciones de la más diversa índole; de ahí que sea posible referirse a la existencia de un «régimen de consolidación de la paz» en el sistema de las Naciones Unidas.

\footnotetext{
16 Aquí entendida como «Carta de la Organización de las Naciones Unidas».

17 Las expresiones consolidación de la paz y «construcción del Estado» se emplean indistintamente para referirse al mismo problema, a las mismas acciones y a los mismos objetivos de corto y mediano plazo. Sin embargo, aquella puede distinguirse de esta en cuanto al sujeto activo (las Naciones Unidas), su base jurídica (la Carta) y el acento en el objetivo de consolidación de la paz.
} 
M. Cecilia AÑaños • La consolidación de la paz...

La expresión "consolidación de la paz» aparece por primera vez en 1992 con el informe «Un Programa de Paz» del Secretario General Boutros B. Ghali, quien lo, concibe como una etapa posterior a los conflictos consistente en "medidas destinadas a individualizar $y$ fortalecer estructuras que tiendan a reforzar y consolidar la paz a fin de evitar una reanudación del conflicto.» ${ }^{18}$ A partir de entonces se han avanzado definiciones que la consideran como un «proceso social complejo de rehabilitación, reconstrucción y renovación» ${ }^{19}$, destinado a superar los efectos de la guerra y asegurar los procesos de paz. Estas conceptualizaciones se basan en un concepto amplio de paz -en su acepción negativa y positiva-, que va más allá de la simple terminación física del conflicto y apunta a superar sus causas estructurales y efectos, incluyendo el diseño de una política de desarrollo sostenible.

Al igual que la «construcción del Estado", la consolidación de la paz es una empresa de enorme complejidad y magnitud, y por ende, extremadamente cara. Comprende medidas múltiples de corto, mediano y largo plazos que se traducen en mandatos robustos y multidimensionales compuestos de elementos civiles y militares, que incluyen la más amplia gama de acciones no agotables en una lista taxativa, sino implementables y adaptables a la

18 UN Doc. A/47/277-S/24111 del 17.06.1992, párr.21.

19 Matthies, V., (1995) Murithi, T., (2009), p. 3; Voorhoeve, J. (2007) J, p. 19. particularidad y a las necesidades del país receptor. Abarcan desde la simple asistencia de emergencia y humanitaria, la repatriación, la integración de refugiados, la desmovilización y el desarme; pasan por restablecer el orden estatal, la seguridad interna, la rehabilitación de estructuras administrativas, de gobierno y la justicia transicional, el Estado de derecho, la sociedad civil, la reintegración, la reconciliación y la rehabilitación y llegan hasta medidas de desarrollo socioeconómico.

La ciencia de la investigación para la paz y sobre los conflictos ha desarrollado criterios de funcionalidad y efectividad de la consolidación de la paz que se rigen, además del principio de la paz positiva, por otros principios como el de imparcialidad, inclusión, subsidiariedad y transitoriedad. El principio de imparcialidad prohíbe el favorecimiento subjetivo de una de las partes del conflicto; el de inclusión exige que todos los actores estén inmersos en el proceso de paz; los de subsidiariedad y transitoriedad exigen que los mandatos solo operen de forma supletoria y hasta que el Estado esté en la condición de autogobernarse y autoadministrarse. Principios que habrán de tenerse en cuenta para el análisis de los casos concretos ${ }^{20}$.

En el campo operacional y teniendo en cuenta los actores que la llevan a cabo, la consolidación de la paz puede

20 A esto vid. Steiner, M., pp 61-73, y el Informe del Grupo sobre las Operaciones de Paz de las Naciones Unidas (informe Brahimi) párr. 50, UN Doc. A/55/305S/2000/809 (21. 08. 2000). 
adoptar dos formas diferentes: operaciones realizadas por las Naciones Unidas y operaciones autorizadas por el Consejo de Seguridad. Las primeras se diferencian, según el grado de la intensidad de la intervención, en: a) acompañamiento (apoyo) en la construcción del país, controlando y supervisando el cumplimiento de las normas internacionales sin que haya funciones soberanas (Namibia); b) delegación de parte de la administración del país a las Naciones Unidas con funciones soberanas, existiendo una autoridad local con derecho a voz (Camboya); y c) toma total del poder estatal sin acto de delegación y basado en la Carta (UNOSOM II/Somalia, UNMIK/Kosovo). Las segundas son emprendidas y ejecutadas por terceros, generalmente potencias occidentales, como en los casos de UNITAF en Somalia, EUFOR/Althea en Bosnia y Herzegovina, Artemis en la R.D. del Congo, ISAF en Afganistán. En este trabajo solo nos ocuparemos de las primeras, por tratarse de medidas propias de la organización.

Mas allá de los fines reconocibles de prestar servicios a Estados que salen de un conflicto y que transmiten el mensaje de neutralidad de este régimen se ecuentran dos áreas de problemas de importancia para el derecho internacional: la naturaleza de los medios y los fines. En cuanto a los medios, la consolidación de la paz se vale de diversas formas y grados de interferencia e intervención en un Estado, que llegan hasta la de asumir funciones soberanas, que originalmente son del dominio exclusivo de este. En cuanto a los fines, trae consigo un tinte ideológico y político, es decir, comprende un esquema de valores y un programa político predefinido orientado al logro de una «buena gobernanza», con estructuras de gobierno democrático liberal y economía de mercado ${ }^{21}$, que incluyen los derechos humanos, el Estado de derecho y la cooperación para el desarrollo. La población destinataria está obligada a forjar su futuro de acuerdo con estos modelos, quedándole escaso o ningún margen de opciones para ordenar, configurar y desarrollar su futuro con plena libertad.

Desarrollo de la CONSOLIDACIÓN DE LA PAZ EN

\section{LAS Naciones Unidas}

La consolidación de la paz constituye la etapa culminante, a la vez que, importante en la práctica de manejo de conflictos de las Naciones Unidas, que desde su fundación en 1945 ha tenido un desarrollo histórico marcado por los cambios de la política mundial. Así, se pueden distinguir en este desarrollo tres fases o momentos:

\section{La Guerra Fría (1945-1990)}

Durante la Guerra Fría las Naciones Unidas estuvieron mayormente imposibilitadas de tomar decisiones en materia de medidas de mantenimiento

21 A lo que Paris llama «liberalización», vid. Paris, R. (2004), p. 5 ss. 
de la paz frente a conflictos inminentes y serios debido al uso frecuente del veto en el Consejo de Seguridad. No obstante, la organización empezó a enviar misiones de mantenimiento de la paz a algunas zonas de conflicto que se conocieron como operaciones de paz (peace keeping) o «cascos azules» y con el tiempo fueran calificadas de "tradicionales» o "clásicas» u «operaciones de primera generación». Se trataba en general de operaciones de observación y verificación del componente militar, cuya responsabilidad principal consistía en supervisar o vigilar el cese al fuego. Sus características esenciales eran el consentimiento del Estado o de las partes en conflicto, la ausencia de medidas de fuerza, la neutralidad e imparcialidad y el uso de armas ligeras solo para la legítima defensa. Estas operaciones de paz, que fueron más de una docena, cumplieron una función de «amortiguador ${ }^{22}$ y fueron movilizadas en conflictos internacionales y excepcionalmente en conflictos internos. Se basaban en un concepto negativo de paz, orientado estrictamente al mantenimiento de la paz internacional. Un ejemplo típico de estas misiones es la Fuerza de las Naciones Unidas para el Mantenimiento de la Paz en Chipre UNFICYP- que desde 1964 está presente en el país.

Nótese que ya algunas de estas operaciones de primera generación fueron incorporando elementos de consolidación de la paz con personal civil y mili-

22 Hufnagel, F.-E., (1996), p 25. tar, como las operaciones de la ONUC ${ }^{23}$ en Congo en 1960/1964, que incluyó la asistencia técnica al país, y la UNTEA $^{24}$ en Nueva Guinea Occidental en 1962/1963, que cumplió funciones de apoyo legislativo, judicial y ejecutivo.

Ya que la Carta no previó el surgimiento de estas operaciones, su base legal se encontró originalmente en el papel mediador de las Naciones Unidas en el marco del arreglo pacífico de controversias del cap. VI de la Carta. A medida que el mandato de estas misiones se fue extendiendo más allá de las prerrogativas de este capitulo sin entrar en normatividad del cap. VII, se ha sostenido que su legalidad se encuentra en un punto entre el capítulo VI y VII de la Carta, esto es, en el llamado «capítulo VI $1 / 2 »^{25}$.

\section{Etapa post-Guerra Fría (1990-} 2005)

La caída del bloque soviético y del balance bipolar mundial trajo como consecuencia la aparición de nuevos

23 «Mision de las Naciones Unidas en el Congo» en virtud de la Res. 143 del Consejo de Seguridad a instancias del gobierno. Considerada como la primera misión más grande de «consolidación de la paz» de las Naciones Unidas, vid. Voorhoeve, op. cit., p. 17.

24 «Autoridad Ejecutiva Temporal de la Naciones Unidas» con el apoyo militar de la UNSF (Fuerza de Seguridad de las Naciones Unidas en Nueva Guinea Occidental) a raiz del conflicto entre Indonesia y Holanda por este territorio y con el consentimiento de estos países.

25 Hufnagel, F.-E., (1996), p. 30; Payandeh, M. (2005), pp. 254 ss. 
conflictos en Estados que pertenecieron a este bloque y en países del Tercer Mundo, o el recrudecimiento de los ya existentes durante la Guerra Fría, haciéndose notorios los conflictos de carácter predominantemente interno. El fin de la Guerra Fría influyó también considerablemente en el poder negociador de las Naciones Unidas, y en especial del Consejo de Seguridad, que aumentó a partir de entonces su actividad en el manejo de conflictos gracias al uso menos frecuente o abstinencia del veto. Para dar una respuesta adecuada a tales conflictos, el entonces Secretario General Boutros Boutros-Ghali dio paso a una nueva concepción de «mantenimiento de la paz» mediante su informe «Un Programa de Paz», de 1992. De acuerdo con este, la organización dispone de cuatro niveles de acción: la diplomacia preventiva (preventive diplomacy), el mantenimiento de la paz (peacekeeping), el establecimiento de la paz (peacemaking, peace enforcement) y, por último, la consolidación de la paz postconflicto (post-conflict peacebuilding) ${ }^{26}$.

Paralelamente las misiones y operaciones de paz de las Naciones Unidas aumentaron en número y funciones, así como en el grado de intervención y dieron lugar a un nuevo tipo de operaciones que recibieron el nombre de «operaciones de paz de segunda generación ${ }^{27}$, para distinguirlas de las

26 UN Doc. A/47/277-S/24111 (17.06.1992); vid también suplemento UN Doc. A/50/60S/1995/1 (3.01.1995).

27 Algunos autores distinguen entre opera- operaciones de mantenimiento de la paz (peacekeeping). Su ámbito de aplicación fue más allá del simple mantenimiento de la paz, pues se pudo actuar en conflictos predominantemente internos. Las medidas a su disposición fueron combinándose de elementos civiles y militares, adquiriendo así un carácter complejo. Dentro del componente civil se encontraban tareas de observación de elecciones, ayuda humanitaria, construcción y/o reconstrucción ${ }^{28}$, funciones de gobierno y administración soberana del Estado. El componente militar estaba equipado para intervenir en el conflicto incluso haciendo uso de la fuerza para proteger la población civil y asegurar la ayuda humanitaria.

Por ser las tareas de construcción y/o reconstrucción, así como las de administración y gobierno, una nota característica de estas operaciones de paz, se puede decir sin lugar a duda que revisten también el carácter de consolidación de la paz, toda vez que fueron realizadas sobre la base de negociaciones de paz o acuerdos de paz y tuvieron el mandato de construcción o reconstrucción, administración y/o gobierno. La «consolidación de la paz» nace precisamente de estas operaciones y se desarrolla primero en ellas para

ciones de paz de "primera", "segunda» «tercera» generación y reservan el de "cuarta» generación a la consolidación de la paz. Entre ellos: Kühne, W., (2005), p. 28; Payandeh, M., (2005), pp. 255 ss. No seguimos esta clasificación ya que resulta difícil diferenciar entre ellas sin caer en grandes confuciones.

28 Hufnagel, F.-E., (1996), p. 212. 
M. Cecilia AÑaños • La consolidación de la paz...

después tomar forma propia a partir del informe «Un programa de paz». Ciertamente, la gran mayoría de las operaciones de paz de «segunda generación» contiene en mayor y menor grado elementos de consolidación de la paz, y por tanto, pueden constituirse como tales ${ }^{29}$.

Un balance general de la consolidación de la paz en esta etapa solo puede hacerse al analizarse todas y cada una de las operaciones de cara a la situación actual de los países receptores, tarea de dimensiones colosales. Sin embargo, un balance provisional arroja más resultados negativos que positivos y que no pueda mencionarse algún caso ejemplar de consolidación de la paz. Los países

29 Sin pretender ser una lista completa, cabe mencionar: GANUPT en Namibia (1989/90); APRONUC en Camboya (1992/93); ONUMOZ en Mozambique (1992/94), ONUSOM II en Somalia (1993/95); UNMIH (1993), UNSMIH, UNTMIH (1997), MIPONUH (1998) y MINUSTAH (a partir del 30 de abril de 2004) en Haiti; UNAMIR en Rwanda (1993/96); UNMOT en Tayikistán (1994/2000); UNOSAL en El Salvador (1991/95); UNOMIL en Liberia (1993/97); UNMIBH en Bosnia-Herzegovina (1995/2002); MONUA en Angola (1997/1999); MINURCA en la República Centroafricana (1998/2000); UNMIK en Kosovo (desde 1999); UNTAET (1999/2002); UNMISET (2002/2005), UNMIT (2006) en Timor Oriental o Timor Leste; MONUC en la República Democrática del Congo (desde 1999); UNAMSIL en Sierra Leona (1999/2005); UNAMA en Afganistán (desde 2002); ONUB en Burundi (2004/2006); ONUCI en Côte d'Ivoire (desde 2004); UNMIS en Sudán (desde 2005). Para un estudio objetivo de estas operaciones en la década de 1990 vid. Paris, R., (2004) y para una presentación general y práctica de las mismas vid. Voorhoeve, J., (2007). que fueron objeto de estas operaciones, siguen enfrentando serios problemas de legitimación, gobernanza, seguridad, estabilidad y desarrollo económico y viabilidad general ${ }^{30}$.

\section{La institucionalización de la consolidación de la paz}

El impulso dado a acciones de construcción y reconstrucción de las Naciones Unidas a partir de los años noventa llevó a la necesidad de hacer más eficiente el manejo y la prevención de los conflictos y superar las deficiencias en la coordinación de las tareas de consolidación de la paz postconflicto. Para ello, se creo la Comisión de Consolidación de la Paz (CCP) a iniciativa del entonces Secretario General Kofi Annan en su informe „Un concepto más amplio de la libertad: Desarrollo, Seguridad y Derechos Humanos para todos» ${ }^{31}$, que fue aprobado en la Cumbre Mundial de las Naciones Unidas en 2005 "para atender a las necesidades especiales de los países que salen de situaciones de conflicto con miras a lograr la recuperación, la reintegración y la reconstrucción y ayudarlos a sentar las bases de un desarrollo sostenible» ${ }^{32}$.

\footnotetext{
30 Bowden, B. et al. (eds.), p. 2.

31 UN Doc. A/59/2005 (21.03.2005), párr. 114 ss., basado a la vez en las recomendaciones del informe «Un mundo más seguro: la responsabilidad que compartimos» del Panel de Alto Nivel sobre las Amenazas, los Desafíos y el Cambio de 2003, UN Doc. A/59/565 (2.12.2004), párr. 261 ss.

32 Documento Final de la Cumbre Mundial
} 
Sellan el nacimiento de este órgano las resoluciones del Consejo de Seguridad y de la Asamblea General ${ }^{33}$.

La Comisión de Consolidación de la Paz se crea pues con el objetivo central de «agrupar a todos los agentes interesados para reunir recursos, proponer estrategias integrales de consolidación de la paz y recuperación después de los conflictos y ofrecer asesoramiento sobre esas estrategias. ${ }^{34}$. Se trata de una entidad intergubernamental dedicada principalmente a la coordinación y asesoría con funciones de monitoreo, revisión y alerta. Actúa a pedido expreso del país interesado y sus decisiones se toman por consenso. Está compuesto por dos órganos principales: un Comité permanente de Organización de 31 miembros $^{35}$ y Comités Especiales por países ${ }^{36}$, y cuen-

2005, UN Doc. A/RES/60/1 (24.10.2005), párr. 97.

33 Res. 1645 del Consejo de Seguridad, UN Doc. S/RES/1645 (20.12.2005) y Res. 60/180 de Asamblea General, UN Doc. A/ RES/60/180 (30.12.2005).

34 UN Doc. A/REs/60/1, párr. 98. Para un análisis más amplio sobre la creación de este órgano vid. Bermejo, R. Y E. LópezJacoiste, (2006), pp. 50 ss.

35 Compuesto a la vez por siete miembros del Consejo de Seguridad, siete del ECOSOC, siete de la Asamblea General, cinco Estados con mayor donación de dinero, cinco Estados con mayor contingente de tropas e instituciones donantes.

36 Composición variable que principalmente incluye miembros del Comité de Organización, del Estado afectado, organizaciones internacionales y/o regionales, contribuyentes financieros y de tropas en el país, un representante principal de las Naciones Unidas en el país e instituciones financieras relevantes. ta con la asistencia de una Oficina de apoyo para la Consolidación de la Paz, dependiente de la Secretaría General, y de un Fondo para la Consolidación de la Paz, con contribuciones voluntarias para la financiación de los programas correspondientes incluyendo casos de emergencia. Un año después de su creación, en 2006, esta entidad inició sus actividades como órgano subsidiario del Consejo de Seguridad y ha asistido a Estados como Burundi, Sierra Leona, Guinea Bissau, y la República Centroafricana, elaborando estrategias integradas de consolidación de la paz a corto y mediano plazo. Aun es prematuro hacer un balance de su actuación.

\section{El marco legal de la CONSOLIDACIÓN DE LA PAZ}

La práctica de consolidación de la paz de las Naciones Unidas posee o debe poseer un marco legal yacente en el derecho internacional positivo. ¿Cuál es entonces su base jurídica? Para responder a esta cuestión, indagaremos si hay posibles normas de justificación. Una primera fuente general de esta se encuentra en el consentimiento. Por ser la consolidación de la paz una actividad aplicable a países en la fase de postconflicto, se hace ante todo necesario diferenciar dos regímenes legales distintos en el derecho internacional: el ius post bellum o derecho postbélico y el régimen de la Carta de las Naciones Unidas. En lo que sigue nos referiremos al consentimiento así como a estas dos posibilidades. 
M. Cecilia AÑaños • La consolidación de la paz...

\section{El consentimiento}

El consentimiento, que no está regulado por la Carta pero que forma parte del derecho consuetudinario internacional, es una causa de exclusión de la ilicitud de un acto, y por tanto, de la responsabilidad internacional ${ }^{37}$. Para la consolidación de la paz el consentimiento del Estado afectado tiene gran importancia jurídica y práctica. Por un lado, legitima este porque la manifestación de la voluntad soberana del Estado receptor deja intacto el derecho de autodeterminación de los pueblos, de modo que no existe violación de la soberanía territorial cuando un Estado consiente en que fuerzas extranjeras actúen en su territorio o expresamente las invita. Por otro lado, el consentimiento se relaciona directamente con el éxito de la consolidación de la paz, como puede verse de la historia de la práctica de las Naciones Unidas. A mayor consenso, apoyo y/o aceptación de la población y grupos políticos y sociales más importantes mayores posibilidades de éxito ${ }^{38}$.

En la práctica aparecen problemas para determinar cuándo y en qué cir-

37 Art. 20 del Proyecto de Artículos sobre la Responsabilidad de los Estados por actos internacionales ilícitos, CDI, sesión 53, 2001, UN Doc. A/56/10; Art. 19 Informe de la Comisión de Derecho Internacional sobre las reglas de la responsabilidad internacional de las organizaciones internacionales, UN Doc. A/64/10 (2009).

38 Schaller, Ch. (2006), "'Peacebuilding und ,ius post bellum'. Völkerrechtliche Rahmenbedingungen der Friedenskonsolidierung nach militärischen Interventionen», Berlin, SWP-Studie, p. 11. cunstancias es válido el consentimiento, sobre todo en casos de ausencia del poder estatal efectivo como producto de un conflicto interno. En tal situación, estarían llamados a darlo el pueblo o las partes en el conflicto. En el primer caso habría que recurrir a algún medio de consulta popular como el plebiscito, aunque en la práctica sea difícil registrar un consentimiento válido e inequívoco del pueblo no organizado. En el segundo caso, existe el gran peligro de no alcanzar un consentimiento auténtico, debido a acuerdos frágiles o parciales que excluyen a una o varias partes importantes en el conflicto o ha sido logrado bajo presión. En vista de que en tales circunstancias el consentimiento no es posible o este es imperfecto, lo que pueda generar un impasse legal, el Consejo de Seguridad prefiere basar sus medidas de consolidación de la paz en el cap. VII de la Carta, aunque el Estado receptor haya dado su consentimiento.

\section{El ius post bellum}

La consolidación de la paz se aplica a la etapa postconflicto (post bellum) que presupone la terminación del conflicto. Lo primero que hay que dilucidar es si existe una regulación específica para el post bellum en el derecho internacional. El derecho internacional clásico solo conoce de un derecho postbélico (ius post bellum) muy exiguo, cuyas normas regulan la fase de postconflicto con respecto de capitulaciones, cese de fuego y la ocupación (occupatio bellica), y que 
se relacionan con las reglas del ius in bello o derecho internacional humanitario (derecho de La Haya y Ginebra). Debido a que en la consolidación de la paz se trata de la presencia de fuerzas extranjeras en un Estado, nos interesa detenernos en la occupatio bellica, que se define sencillamente como el control de un territorio extranjero ${ }^{39}$.

En principio, toda intervención militar extranjera seguida de la ocupación militar del país afectado constituye una оссираtio bellica y le son aplicables las reglas del derecho de ocupación. Ello se desprende del Art. 42 del Reglamento relativo a las Leyes y Costumbres de la Guerra Terrestre (1907) que da por existente la ocupación cuando un territorio «se encuentra colocado de hecho bajo la autoridad del ejército enemigo». La misma puede ser total o parcial y procede aun sin encontrar resistencia militar ${ }^{40}$, siendo su único requisito que exista evidencia suficiente del establecimiento y ejercicio real de la autoridad del ejército enemigo sobre el área ocupada ${ }^{41}$. Ejemplos recientes de ocupación los dieron Irak y Afganistán por Estados Unidos y países aliados.

El derecho de ocupación ${ }^{42}$ está constituido por un conjunto de normas de

39 Bothe, M. (1982), p. 65.

40 Art. 2 común de los cuatro Convenios de Ginebra.

41 Case concerning armed activities on the Territory of the Congo, I.C.J. Reports (2005), párr. 173.

42 Comprende el Art. 42 y siguientes del Reglamento relativo al Convenio de la Haya sobre las Leyes y Costumbres de la Guerra Terrestre (1907); Art. 47ss, Art 6 párr. 3 del IV Convenio de Ginebra de 1949 y Art. 63 del Protocolo Adicional I. carácter consuetudinario ${ }^{43}$ que regulan la conducta de fuerzas ocupantes en territorio extranjero siempre y cuando esté ausente la debellatio ${ }^{44}$, y tiene la finalidad de proteger los derechos fundamentales de la población del territorio ocupado. Esta regulación pone limitaciones significativas a la potencia ocupante: solo le permite actuar en el territorio ocupado de forma fiduciaria y provisional, esto es, debe ejercer actividades de resguardo del orden público y la seguridad respetando las leyes vigentes y actuando dentro del marco institucional existente -sin construir, cambiar o revolucionar el orden constitucional del lugar. De una lectura más restrictiva de sus normas se infiere una prohibición a la potencia ocupante de privar definitivamente al Estado ocupado del uso de sus derechos soberanos, cambiar la estructuras de poder o de la población, cambiar el régimen u orden jurídico, económico o social, así como influir en la formación de la voluntad política del pueblo. Tales restricciones, que intentan garantizar el statu quo ante del territorio ocupado, no tienen como fin el resguardo de instituciones anacrónicas, sino la función cautelante de proteger la soberanía del Estado frente a una dominación o dictado extranjero y el derecho de autonomía de su población ${ }^{45}$. Una ocupación de carácter transformativo -que conduce

43 Gasser, H.-P. (2004), p. 140.

44 La ausencia de la debellatio exige que el Estado ocupado siga existiendo como tal en virtud del principio de continuidad, quedando solamente restringida su capacidad de acción. Epping, op. cit. (n. 6), p. 13 s.

45 Oeter, S. (2005), p. 43. 
al cambio forzado del sistema político-, como en Irak y Afganistán, está entonces prohibida por el derecho de ocupación.

Cuestión por esclarecer es si el derecho de ocupación es aplicable a las misiones de consolidación de la paz de las Naciones Unidas, cuya práctica al respecto no es clara. En general no se considera que la organización sea una «potencia beligerante ocupante» y por ejemplo en medidas de consolidación de la paz, adoptadas en Somalia, Camboya, Kosovo y Timor Oriental no se refieren al derecho de ocupación sino al cap. VII de la Carta. Sin embargo, ha recurrido al derecho internacional humanitario como derecho general, cuando ha establecido directrices para las operaciones de paz y exigido a las potencias ocupantes en Irak el respeto debido de los Convenios de Ginebra y del Convenio de la Haya de $1907^{46}$.

Aunque las Naciones Unidas no son parte contratante de los Convenios de la Haya y Ginebra, se rigen por el derecho internacional humanitario consuetudinario -y a su parte especial del derecho de ocupación- cuando participen en conflictos armados y ocupen el territorio de un Estado. Mas en vista de que la organización se rige ante todo por el derecho de la Carta, ha de buscarse primero en ella el fundamento de las acciones de consolidación de la paz.

46 Reglas que no se refieren directamente a la fase de postconflicto. Vid. Boletín del Secretario General: Observancia del derecho internacional humanitario por las fuerzas de Naciones Unidas, UN Doc. ST/ SGB/1999/13 (6.08.1999); y UN Doc. S/ RES/1483 (2003), párr. 5.
Entonces, el derecho de ocupación tiene aplicación subsidiaria o general respecto de medidas no cubiertas por convenios especiales o por el cap. VII de la Carta. Con esto se intenta también puntualizar que el derecho de ocupación, como parte del derecho internacional humanitario, no ha sido derogado por el régimen de la Carta ni ha caído en desuetudo ni siquiera en vista de los acontecimientos del $11 / 9^{47}$, tal como se comprueba de uno de los últimos fallos de la Corte Internacional de Justicia ${ }^{48}$.

\subsection{El problema de definición del post bellum}

Un problema que se presenta para la aplicación del derecho internacional a situaciones dadas después de un conflicto es la determinación de la etapa postconflicto (post bellum) en los conflictos modernos ${ }^{49}$, que se caracterizan por su persistencia, reincidencia y hasta agravamiento aún después de firmado un acuerdo de paz y establecido un cese del fuego. Se trata de un período de transición no clasificable dentro de la guerra ni

47 Fleck, D., (2003) pp. 71 ss.; Gasser, H-P. (2008), pp. 422. Cfr. Zwanenburg, M. (2004), pp. 763; Roberts, A. (2006), pp. 580-622.

48 Vid. Case concerning armed activities on the Territory of the Congo I.C.J. Reports (2005), párr. 178. La Corte consideró a Uganda como potencia ocupante en el Congo basándose en el Reglamento relativo al Convenio de la Haya sobre las Leyes y Costumbres de la Guerra Terrestre (1907) y derivó su responsabilidad internacional como tal.

49 Vid. Bowden et al. (Eds.), op. cit. (n. 9), p. 4s. 
de la paz sino situado entre ambas. De ahí que la ciencia política y social lo entienda como un proceso complejo, largo y difícil de transformación de la guerra a la paz y con el peligro de recaer $^{50}$, definición esta que describe de manera fidedigna los últimos casos de conflictos armados de carácter preponderantemente interno, mixto y asimétrico y con nuevas formas de conducción. Las Naciones Unidas han adoptado esta linea conceptual y prefieren tomar el camino práctico de entender la etapa postconflicto como un proceso abierto de transformación a largo plazo y aplicar el derecho de la Carta.

La comprensión de la etapa postconflicto como un proceso de transición no responde a las preguntas de cuándo empieza y termina esta para determinar qué derecho es válido en la fase postconflicto y en qué condiciones ¿El ius in bello, el derecho de ocupación, el derecho de la Carta bajo el cap. VII o el nuevo derecho que establece la potencia ocupante dentro de su acción de reconstrucción? El derecho internacional solo conoce los estados de guerra y paz y no de una parte intermedia o de transición entre ellos. Entonces ¿se hace necesario redefinir la guerra y la paz a la luz de los nuevos desarrollos de los conflictos armados, o hay que abandonar esta tarea y concebir la fase postconflicto como una etapa diferente y nueva en el derecho internacional de los conflictos armados? En esta última dirección se mueve la propuesta de que el el ius post bellum se desarrolle como una tercera etapa en

50 Matthies, (1995), pp 23, 33. el derecho de los conflictos armados, bajo premisas adecuadas a este y que correspondería a una división tripartita entre ius ad bellum, ius in bello y ius post bellum ${ }^{51}$, teniendo en cuenta que ya existe una separación entre el ius ad bellum y ius in bello ${ }^{52}$. Mas esta propuesta pertenece todavía al ámbito de la lege ferenda, mientras tal vacío del derecho es llenado con respuestas y actuaciones oportunas y prácticas que no resuelven en lo sustancial este problema central.

\section{El régimen de la Carta de las Naciones Unidas}

Como las Naciones Unidas son actor activo en la consolidación de la paz y en sus decisiones y actuaciones se rige por su tratado constitucional, la Carta, en ella debe buscarse el sustento normativo de la actividad. Esta tarea parece ser a primera vista imposible, puesto que la Carta no la previó sino que ella se desarrolló tiempo después de creada la organización. Sin embargo dentro de la carta, se pueden encontrar posibles normas aplicables.

\subsection{El régimen internacional de administración fiduciaria}

En vista de que las tareas de consolidación de la paz implican el gobierno

Stahn, C., (2006) pp. 921 ss.

52 Regímenes jurídicos distintos y separados por razones humanitarias. El ius ad bellum solo permite la intervención militar como excepción a la prohibición del uso de la fuerza y el ius in bello son reglas de conducta durante la guerra o conflictos armados. 
M. Cecilia AÑaños • La consolidación de la paz...

y administración de un territorrio determinado, una primera fuente normativa se encontraría en el régimen de administración fiduciaria regulado por los cap. XII y XIII de la Carta, que autorizan a la organización para administrar transitoriamente territorios en situación de descolonización o incapacitados para gobernarse, con el fin de lograr el autogobierno e independencia, y el bienestar de su población.

Sin embargo subsumir Estados en etapa de postconflicto en el cap. XII de la Carta no es jurídicamente posible. El régimen de administración fiduciaria no se permite para Estados miembros de las Naciones Unidas en virtud del derecho de soberanía de que todos gozan, tal como lo expresa el Art. 78 de la Carta. Con ello se descarta este capítulo como fundamento jurídico de las actividades de consolidación de la paz. Mas ello no obsta para aplicar analógicamente algunas disposiciones de ese capitulo a las medidas de consolidación de la paz cuando las Naciones Unidas las ejerzan en el territorio de un Estado. Ellas deben concebirse como normas aplicables y a la vez que como límites a las facultades del cap. VII y a los poderes implícitos del Consejo de Seguridad. En especial, han de mencionarse la obligación de proteger los derechos humanos del Art. 76 (c) y de contribuir al mantenimiento de la paz del Art. 84, la igualdad de trato del Art. 76 (d), la reserva de los derechos existentes del Art. 80 y la disposición general del Art. 81.

\subsection{El mantenimiento de la paz}

Por tratarse en la consolidación de la paz de medidas complejas que llevan elementos tanto civiles como militares y que afectan en mayor y menor medida diversos bienes jurídicos de los Estados, su base legal debe buscarse en el marco de prerrogativas amplias otorgadas al Consejo de Seguridad, que se encuentran en el ámbito de la seguridad colectiva, y más específicamente, en las disposiciones de la Carta sobre la resolución de conflictos. Para ello vienen a tallar las normas de los cap. VI («peligro a la paz») y VII («amenaza a la paz»), que otorgan al Consejo de Seguridad poderes especiales para el mantenimiento de la paz en virtud del Art. 24 (2) de la Carta.

Mas es el cap. VII el que adquiere mayor relevancia por tener carácter obligatorio para los demás Estados (Arts. 25, 48, 103 de la Carta) y excluir la aplicabilidad de la norma de no intervención del Art. 2(7) de la Carta. Así pues, las medidas colectivas militares, que son una excepción a la prohición general del recurso a la fuerza, requerirán del Art. 42 de la Carta. Las medidas colectivas que implican el grado más alto de intervención -gobierno y administración civil directa-, por el hecho de afectar derechos soberanos y el derecho de autodeterminación de los pueblos, necesitan el respaldo del Art. 41 de la Carta. Ejemplos paradigmáticos de estas últimas son las misiones UNMIK/ Kosovo y UNTAET/Timor Oriental. Para que procedan tanto las medidas 
colectivas del Art 41 como del 42, se requiere previamente la determinación de la existencia de una «amenaza a la paz» por el Consejo de Seguridad, tal como lo prevé el Art. 39 de la Carta. Puesto que el término «amenaza a la paz» no está definido ni tampoco existen criterios específicos para determinarlo, el Consejo de Seguridad posee aquí un amplio margen político de interpretación y actuación. No obstante, el concepto de "amenaza a la paz» debe ser aproximado de acuerdo con las disposiciones de la Carta y según la práctica del Consejo de Seguridad.

La pregunta que surge es cómo subsumir el esquema de la consolidación de la paz dentro de la «amenaza a la paz». ¿Pueden constituir los Estados en su fase de postconflicto una "amenaza a la paz»? A primera vista la respuesta es negativa, porque precisamente la fase de postconflicto supone la terminación o superación del conflicto armado en pos de la reconstrucción y recuperación. Esta apreciación es correcta mientras estemos empleando el concepto tradicional o negativo de paz, entendido como ausencia de guerra, que a su vez hace muy difícil o impide ordenar las medidas de consolidación de la paz dentro del cap. VII de la Carta.

Debido a este impasse normativo, buena parte de la doctrina anglosajona y germana ha recurrido a una interpretación «objetiva-dinámica» del Art
39 de la Carta $^{53}$ que se vale de una interpretación teleológica y se apoya en la doctrina de los poderes implícitos (implied powers), con el fin de adecuar el concepto de «amenaza a la paz »a los nuevos desarrollos de la práctica de las Naciones Unidas. Según esta postura, el concepto corriente de paz, entendido como ausencia de guerra, resulta ser insuficiente frente a los nuevos retos internacionales y por tanto, requiere una ampliación o un concepto unitario de paz, que abarcaría tanto el concepto negativo de paz de los Art. 2(4), Art. 24(1) y del sistema de mantenimiento de la paz de los cap. VI y VII como el concepto positivo de paz, identificable en el preámbulo, en las cuestiones económicas y sociales y en el régimen de administración fiduciaria de la Carta ${ }^{54}$. Esta forma ampliada de la «paz» estaría en consonancia con el fin primordial del mantenimiento y restitución de la paz mundial de las Naciones Unidas, concluyéndose así que las operaciones de paz de segunda generación, y más específicamente las de consolidación de la paz promueven los fines de la Carta, y por tanto, concuerdan con la normatividad de la misma. Esta interpretación extensiva se justifica por el cambio dramático de las circunstancias desde la caída del bloque soviético, que tiene

53 Condicionada: 1) a que existan cambios de las circunstancias externas, 2 ) a las que el Consejo de Seguridad reacciona con una nueva práctica interpretativa, y 3 ) que sea aceptada por los demás miembros, Hufnagel, F.-E., op. cit. (n. 11), p. 235 s.

54 Art. 1 (2), (3), Art. 13, Art. 55 y Cap. XII de la Carta. 
M. Cecilia AÑaños • La consolidación de la paz...

a los «Estados fallidos» como uno de los fenómeno nuevos derivados de ella.

La tesis de la paz positiva como contenido del Art. 39 de la Carta es controvertida. Un argumento en su contra sostiene que es inadecuado, porque se estaría otorgando al Consejo de Seguridad la facultad adicional de garantizar el bienestar general de la población mundial, función que se acercaría a la de un gobierno mundial y que no puede estar en la intención de los Estados. Este razonamiento solo acepta como válido el concepto de paz negativa, siendo suficiente los conceptos de «amenaza» y "paz internacional» para extender la aplicación del Art 39 a sujetos no estatales, como el pueblo, y a conflictos internos ${ }^{55}$. Posición esta que sin embargo queda aislada frente a las tendencias doctrinarias mayoritarias que adhieren a los cambios experimentados por las Naciones Unidas. Otro argumento en contrario es la falta de representatividad del Consejo de Seguridad, pese a que sus actuaciones gozan de legalidad gracias a la Carta y están revestidas de cierta legitimidad al actuar en nombre de la "comunidad internacional». Legitimidad que, sin embargo, está siendo cuestionada por diversos hechos relacionados entre sí, principalmente porque el destino de un Estado y de su población queda en manos de cinco Estados de un total de 191 miembros de la organización; por su composición desigual y su carácter esencialmente político que lleva a pro-

55 Wollenberg, S. (2007), pp. 184 ss. cesos de decisión no transparentes y negociables, y que son a la vez causa de decisiones contradictorias, parciales y selectivas.

Los intentos de incorporar el concepto positivo de paz dentro del mantenimiento de la paz de la Carta vía interpretación, concuerda pues con las últimas prácticas y tendencias de las Naciones Unidas en materia de mantenimiento de la paz, vistas en las propuestas de reforma de diversas comisiones ad hoc. La práctica de las Naciones Unidas de acuerdo con esta nueva interpretación empezó con UNOSOM II en Somalia y ha continuado hasta el presente, cimentando el concepto positivo de paz y el concepto ampliado de amenaza y seguridad, que permiten extender el radio de actuación de las Naciones Unidas a conflictos internos o casos de inestabilidad interna. Una modificación de la Carta por la vía de interpretación hará necesario precisar y delimitar el concepto aún indeterminado de paz positiva, ello en virtud del principio de la seguridad jurídica y teniendo en cuenta que el Art. 39 ha sido objeto de considerables ampliaciones.

\subsection{La «responsabilidad de} proteger»

La «responsabilidad de proteger» es un concepto que surgió en 2001 cuando la Comisión Internacional sobre Intervención y Soberanía de los Estados $(\text { CIISE) })^{56}$ presentó un informe extenso

56 ICISS, The Responsibility to Protect, diciembre de 2001, accesible en español: 
intitulado «Responsabilidad de Proteger». En este se exponen tres áreas de responsabilidad de la comunidad internacional: las de prevenir, proteger y reconstruir. El aspecto central de la idea es que la comunidad internacional no solo tiene una prerrogativa de protección (ayuda) a una población determinada sino una obligación subsidiaria en caso de que el Estado no cumpla sus obligaciones o no esté en situación de hacerlo. La tercera área de responsabilidad, la «responsabilidad de reconstruir», coincidiría con la consolidación de la paz y le otorgaría a esta última una base jurídica, presuponiendo que se trata de una norma de derecho internacional. El mismo informe considera la «responsabilidad de proteger» como una "norma emergente de derecho internacional».

La doctrina de la «responsabilidad de proteger» que subyace en este informe es controvertida y es objeto de arduos debates en la Asamblea General. Los Estados han incorporado el concepto en el Documento Final de la Cumbre Mundial 2005 con sustanciales recortes frente a su texto original. Así, están dispuestos a reconocer una responsabilidad de proteger como deber mas no como obligación, y solo en los casos de genocidio, crímenes de guerra, depuración étnica y crímenes de lesa humanidad. Asimismo, aceptan medidas derivadas de este concepto solo dentro del marco de la Carta y han acordado seguir examinandolo ${ }^{57}$, lo que significa

$<$ http://www.iciss.ca/pdf/Spanish-report. pdf $>$ (4.10.2008).

57 Vid. Documento Final de la Cumbre Mun- que no se reconoce la existencia de una norma de derecho internacional. Para que la «responsabilidad de proteger» surja como una norma consuetudinaria del derecho internacional tendrá que desarrollarse de la práctica internacional (consuetudo) y ser aceptada por los Estados como norma de derecho internacional (opinio juris). Tal práctica es aún inexistente y una opinio juris no puede formarse debido a las fuertes reticencias y objeciones de la mayoría de Estados miembros de las Naciones Unidas $^{58}$. La «responsabilidad de proteger» queda entonces descartada como justificación jurídica para la consolidación de la paz.

\section{LÍMITES JURÍDICOS DE LA CONSOLIDACIÓN DE LA PAZ}

Las amplias facultades del Consejo de Seguridad bajo el cap. VII de la Carta, que mediante una interpretación extensiva del Art. 39 de la Carta hace posible decidir también sobre medidas de consolidación de la paz no son inagotables sino tienen sus límites legales en el

dial 2005, UN Doc. A/RES/60/1 (24.10.2005), párr. 138-140. Vid. también modificaciones pertinentes del proyecto revisado del Documento Final de la Cumbre 2005, accesible en: <http://www.reformtheun.org/index.php/articles/1662\%3E> (4.10.2008).

58 Para mayor profundización vid. Añaños Meza, M. C. (2010), La «Responsabilidad de Proteger» en Naciones Unidas y la Doctrina de la «Responsabilidad de Proteger", Anuario Mexicano de Derecho Internacional X-199-244. 
documento que la creó, la Carta. El Art. 24 (2) restringe las facultades especiales del Consejo de Seguridad al ámbito de la seguridad colectiva y de régimen internacional de administración fiduciaria. Mas los límites materiales de importancia se encuentran en los fines y principios de los Art. 1 y 2 de la Carta y en normas de derecho internacional, quedando prohibida toda actuación arbitraria de la Organización. Las normas y principios que entran en juego son: el derecho de soberanía e igualdad de los Estados, el derecho de autodeterminación de los pueblos, la norma de ius cogens de prohibición absoluta del uso de la fuerza, la prohibición de la intervención, los derechos humanos, el Estado de derecho, el principio de proporcionalidad y la prohibición de la selectividad. Asimismo el cap. XII de la Carta, las reglas especiales para el régimen de ocupación y, por último, la norma de Jus cogens del derecho a la existencia de los Estados ${ }^{59}$. En lo que sigue trataremos las que tienen mayor relevancia para la consolidación de la paz.

\section{La soberanía estatal}

La soberanía estatal es un concepto complejo que tiene diversas acepciones.

59 También referido como «derecho fundamental de supervivencia» de los Estados. Al respecto, vid. Opinión Consultiva de la Corte Internacional de Justicia sobre la legalidad de la amenaza o el empleo de armas nucleares, I.C.J. Reports (1996), p. 226, párr. 96. Vid. Schaller, Ch., op. cit. (n. 38), p. 12.
Es el derecho de todo Estado a que se respeten su existencia y su personalidad jurídica, lo que incluye el derecho de elegir y desarrollar su sistema político, económico, social y cultural sin ingerencias de otros Estados ${ }^{60}$. Se manifiesta de forma externa -reconocimiento recíproco de los Estados como sujetos de derecho sin sometimiento a una autoridad supraestatal-, y de forma interna -el Estado como máxima autoridad en su territorio. La soberanía estatal es también un principio constitucional del derecho internacional ${ }^{61}$, reconocido en el Art. 2 (1) de la Carta como «principio de igualdad soberana», del cual derivan ciertas normas iusinternacionales que garantizan su protección, como la prohibición del uso de la fuerza, la norma de no intervención y el derecho a la independencia e igualdad de los Estados.

La consolidación de la paz bajo el cap. VII de la Carta precisamente deja en suspenso dos normas que garantizan la protección de la soberanía estatal: la prohibición de la intervención del Art. $2(7)^{62}$ y la prohibición del uso de la fuerza del Art. 2(4). En cuanto a la primera, de darse el caso específico

60 Schaller, Ch., (2006), p. 19.

61 Carrillo Salcedo, J.A. (1976), pp. 90, 95.

62 Norma que prohibe influir en la formación de la voluntad política de un Estado y ejercer acciones que caen dentro de su competencia soberana. Obliga a las $\mathrm{Na}-$ ciones Unidas en el Art. 2(7) de la Carta y a los Estados como norma consuetudinaria de derecho internacional. Vid. Caso Concerniente a las Actividades Militares y Paramilitares dentro y contra Nicaragua, I.C.J. Reports, 1986, párr. 202. 
de administración directa del Estado, queda suspendido el ejercicio de ciertos derechos soberanos, a excepción del núcleo esencial de la soberanía estatal, que no está sujeto a afectación y está protegido frente a las medidas del cap. VII de la Carta. A él pertenecen el derecho de existencia del Estado y el derecho de disponer sobre el territorio propio ${ }^{63}$. Suspensión que solo es válida si es de carácter transitorio y apunta al logro del ejercicio autónomo de la soberanía. En cuanto a la segunda, las medidas de consolidación de la paz pueden valerse del uso de la fuerza de no haber consentimiento ni acto de delegación, o de ser estos frágiles, a condición de que sea autorizada por el cap. VII.

\section{El derecho de autodeterminación de los pueblos}

El derecho de autodeterminación de los pueblos consiste en el derecho de ser libre de toda determinación por fuerzas externas, lo que otorga el título de decidir sobre su propio estatus político, incluyendo la creación de un nuevo Estado, la determinación de su forma, estructura constitucional y orden institucional. Sujetos titulares son el pueblo en su conjunto, y en casos determinados, las minorías y la población colonial, pero su ejercicio corre a cargo del Estado, quien ejerce su representación a nivel internacional ${ }^{64}$. En cuanto a su status jurídico, se trata pues, en el

63 Wollenberg, S., (2007), p. 208 ss.

64 Correspondiéndole al pueblo una compe- derecho de autodeterminación de los pueblos, de una norma iusinternacional de carácter jus cogens, y además de «uno de los principios elementales del moderno derecho internacional con efecto erga omnes» ${ }^{65}$ Se conoce como principio de legitimación de todo el ordenamiento iusinternacional ${ }^{66}$ y núcleo fundamental del derecho consuetudinario internacional. Al igual que la soberanía estatal, este derecho posee un núcleo esencial no puesto al alcance del cap. VII de la Carta y que consiste en la libertad de toda dominación extranjera, garantizada por el derecho de participar en el gobierno propio ${ }^{67}$.

Como norma de jus cogens anclada en los Art. 1(2), 55 de la Carta y en numerosos convenios y documentos de las Naciones Unidas ${ }^{68}$, obliga tanto al Consejo de Seguridad como a sus órganos, quienes deberán respetar este derecho incluso actuando bajo el cap. VII de la Carta. Para las tareas de consolidación de la paz, ello significa que

tencia subsidiaria, vid. Pfarr, V., pp. 108 ss. (2007)

65 Reafirmación de su carácter de obligación erga omnes y de ser uno de los principios esenciales del derecho internacional contemporáneo en: Opinión Consultiva de la Corte Internacional de Justicia sobre $\mathrm{Na}$ mibia, I.C.J. Reports (1971), p. 19 y también sentencia sobre Timor Oriental (Portugal c. Australia), I.C.J. Reports (1995), párr. 29.

66 Thürer, (1996), p. 15.

67 Wollenberg S., (2007), p. 211 s.

68 Entre ellos el Art. 1 de los Pactos Internacionales de derechos humanos y la Declaración sobre los Principios del Derecho Internacional, UN Doc. A/RES/2625 (XXV) del 24.10.1970. 
este derecho está garantizado cuando el pueblo no solamente es beneficiario de una nueva organización estatal sino su autor o causante ${ }^{69}$, lo que exige reconstruir según las ideas de la población y con su participación plena; indagar y considerar ampliamente la voluntad del pueblo mediante mecanismos de consulta y procedimientos democráticos ${ }^{70}$, y transferir efectivamente al pueblo las funciones esenciales del Estado así como sus competencias soberanas. La obligación de establecer mecanismos de consulta para conocer la voluntad del pueblo no debe confundirse con la práctica usual de establecer determinadas estructuras democráticas o legitimar un gobierno determinado ${ }^{71}$.

Sin embargo, la práctica de consolidación de la paz de las Naciones Unidas se extiende más allá de la fijación de condiciones fundamentales generales para la formación de la voluntad políti$\mathrm{Ca}^{72}$. El problema de la legalidad aparece cuando se intenta contruir o reconstruir un Estado según el modelo de Estado constitucional moderno, con su democracia liberal y economía de mercado, interfiriendo profundamente en la competencia de autodeterminación sobre el orden estatal y amenazando preformar sosteniblemente el proceso político posterior en beneficio de determinados

69 Pfarr, (2007), p. 118.

70 Como los de referendo, plebiscito, convocatoria a elecciones y sufragio en decisiones fundamentales sobre la organización política del territorio.

71 Wollenberg, S., (2007), p. 244.

72 Oeter, (2005), p. 47. intereses sociales ${ }^{73}$. En estos casos se trata de una afectación al derecho de autodeterminación, aun siendo la medida de carácter provisional y teniendo como objetivo el goce posterior y sostenible del derecho de autodeterminación.

\section{El Estado de derecho}

El Estado de derecho es un principio de gobierno que, basado en la prohibición de la arbitrariedad y el principio de legalidad, prevé la sujeción jurídica del poder al derecho mediante el control autónomo de las medidas estatales, tanto ejecutivas como legislativas, creándose para ello estructuras institucionales y procedimientos especiales. Dentro de sus principios elementales están la igualdad de todos ante la ley, la igual aplicabilidad de todas las leyes y el uso responsable del poder político y de acuerdo con las normas constitucionales. Esta categoría de orden constitucional, que pertenecía a la esfera interna del Estado y por tanto caía dentro de su competencia soberana, comenzó a valorarse en el plano internacional recién a partir de la disolución del bloque soviético y ha llegado a adquir suma importancia en las actividades de "construcción del Estado» y de consolidación de la paz. Es así que el establecimiento de un orden social-político bajo el Estado de derecho (rule of law) constituye actualmente uno de los objetivos centrales de

73 Oeter, op. cit., p. 43. 
las Naciones Unidas en sus tareas de consolidación de la paz ${ }^{74}$.

La reciente y abundante práctica de las Naciones Unidas en la promoción y establecimiento del Estado de derecho ${ }^{75}$ no ha ido de la mano con la claridad de su status jurídico en el derecho internacional. Por un lado, hay inseguridad en su carácter de norma iusinternacional y por el otro en el derecho internacional no existe un concepto válido que fije su contenido y extensión. En cuanto a su carácter de normas de la Carta no se desprende ninguna obligación de los Estados de observar y realizar el Estado de derecho ni un derecho de las Naciones Unidas a exigirlo, aunque podría surgir una obligación internacional correspondiente como principio general de derecho, según el Art. 38 (c) del Estatuto de la Corte Internacional de Justicia. Mientras tanto, la exigencia de las Naciones Unidas que los Estados

74 Vid. informe del Secretario General sobre el Estado de derecho y la justicia de transición en las sociedades que han sufrido o sufren conflictos, UN Doc. S/2004/616 (3.08.2004), accesible en: <http://www. un.org/spanish/docs/report04/repl04. htm> (22.10.2008); también su informe «Uniting our strengths : Enhancing UN support for the rule of law», UN Doc. A/61/636-S/2006/980 (14.12.2006); Vid. Farrall, J., «Impossible expectations? The UN Security Council's promotion of the rule of law after conflict» en: Bowden et al. (Eds.), op. cit. (n. 9).

75 Ejemplos más sobresalientes en Haiti (MINUSTAH) y Liberia (UNMIL). Al respecto vid. Farrall, J., «Impossible Expectations? The UN Security Council's promotion of the rule of law after conflict», Bowden, B. et al. (Eds.), op.cit. (n. 9), p. 148ss. observen el Estado de derecho debe sujetarse a las reglas del consentimiento y al derecho de autodeterminación de los pueblos, lo que significa que debe ser conscientemente aceptado y forjado por la población misma y adecuarse a las necesidades y condiciones económicas, sociopolíticas y culturales de la sociedad receptora.

En cuanto al problema definitorio, que es relevante para su aplicación, no existe un consenso internacional de lo que debe entenderse por Estado de derecho, a pesar de haberse ocupado de él las Naciones Unidas ${ }^{76}$. El Consejo de Seguridad, interesado en su promoción, se refiere a él ambiguamente mediante términos afines como derecho y orden, fin de la impunidad, resolución de conflictos conforme al derecho, protección y promoción de los derechos humanos y gobernanza según principios democráticos. Los órganos de las Naciones Unidas comprometidos con la consolidación de la paz aplican este principio como un catálogo de medidas a seguir por los Estados receptores, hecho que ha sido objeto de críticas fundadas. Estas proponen que las Naciones Unidas abandonen este programa y se dediquen a apoyar verdaderos procesos de consulta para que sean las comunidades locales las que determinen sus propias prioridades y estrategias en materia

76 Vid. Informe del Secretario General «El Estado de derecho y la justicia de transición en las sociedades que sufren o han sufrido conflictos», UN Doc. S/2004/616 (23.08.2004), párr. 6; Documento Final de la Cumbre Mundial 2005, un Doc. A/ RES/60/1, párr. 134. 
M. Cecilia AÑaños • La consolidación de la paz...

de Estado de derecho; o simplemente que las Naciones Unidas se dedique a objetivos inmateriales como la rehabilitación de las relaciones humanas y la gobernanza, y al restablecimiento de la confianza dentro de la población nacional ${ }^{77}$.

Por otro lado, las Naciones Unidas están obligadas por este principio cuando ejerzan poderes soberanos dentro de un Estado. Se trata aquí de una cuestión de credibilidad y seriedad, de someterse uno mismo a los principios que proclama para no caer en el absurdo. Lamentablemente, la práctica de las Naciones Unidas en sus tareas de administración directa no ha sido coherente en este sentido, sobre todo con los mandatos de UNMIK (Kosovo) y UNTAET (Timor Este), que se exceptuaron de todo control judicial, hecho que socavó su legitimación democrática como autoridad ${ }^{78}$. Estas disconformidades entre lo proclamado y lo actuado tampoco se justifican con el principio de efectividad y el fin de establecer una «democracia» y un Estado de derecho a largo plazo, porque con ello estarían reavivando el lema maquiavélico de que «el fin justifica los medios».

\section{Los derechos humanos}

Las Naciones Unidas conciben los derechos humanos como un medio

77 Vid. Farrall, J., «Impossible expectations? The UN Security Council's promotion of the rule of law after conflict» en: op. cit., p. $153 \mathrm{~s}$.

78 Stahn, C. (2005), p. 151, 156 ss. esencial para alcanzar la paz sostenible y su cumplimiento efectivo y sostenible constituye, junto con el establecimiento del Estado de derecho, un objetivo central de la consolidación de la paz. Para su realización las Naciones Unidas se dedican entre otras tareas a crear instituciones transitorias, superar las injusticias cometidas y perseguir penalmente la violación de los derechos humanos y del derecho humanitario mediante tribunales penales, como los creados para la ex-Yugoslavia, Rwanda, Sierra Leona y Camboya. Esta actividad es respaldada por la abundante normatividad internacional en derechos humanos y por la importancia que estos han adquirido en el mantenimiento de la paz, gracias al impulso que les han dado de las Naciones Unidas en los últimos veinte años. Los Estados han aceptado respetarlos de acuerdo con los Art. 55 y 56 de la Carta, de los cuales deriva el compromiso de promover y respetar en sus Estados el estándar internacional de derechos humanos ${ }^{79}$. En casos de conflictos armados, de respetar las normas de jus cogens del derecho internacional humanitario, expresadas en el Art. 3 común de los cuatro Convenios de Ginebra.

79 Que comprenden las normas universales de derechos humanos conseguidas en la Carta, la Declaración Universal de los Derechos Humanos, los Pactos Internacionales, los convenios especiales, las normas consuetudinarias y normas de jus cogens con obligaciones erga omnes; así como las normas regionales de derechos humanos. Vid. Buergenthal, Th. (1995). 
Mientras que la obligación internacional de los Estados respecto de los derechos humanos es incuestionable, no sucede lo mismo cuando se trata de organizaciones internacionales como las Naciones Unidas, en especial cuando emprenden tareas de consolidación de la paz y asumen funciones soberanas en el país receptor. Existe en estos casos una carencia normativa que la obliga a respetar dicho estándar. La obligación del Art. 56 de la Carta está dirigida directamente a los Estados; igualmente, los Pactos Internacionales de derechos humanos obligan en principio a los Estados dentro de su territorio soberano y no a actores extranjeros. Frente a este vacío jurídico, las Naciones Unidas, actuando bajo el cap. VII de la Carta, no se siente obligada a rendir cuenta de sus funciones gubernamentales, administrativas y cuasi-administrativas en sociedades postconflicto, y se muestra renuente a asumir responsabilidades legales al respecto.

Sin embargo, este vacío normativo parece ser aparente al encontrarse en la Carta y en el derecho internacional vínculos jurídicos que obligan a las $\mathrm{Na}$ ciones Unidas a respetar la normatividad internacional de derechos humanos en sus acciones de consolidación de la paz. Estos se encuentran primeramente en el Art. 1 (3), que fija como uno de los propósitos de las Naciones Unidas «el respeto de los derechos humanos» y la promoción de los mismos; en el Art. 13 (b), así como en los Art. 55 (c) y 55 de la Carta, que también tienen a las Naciones Unidas como destinataria del respeto y promoción de los derechos humanos. Otro vínculo jurídico, que se dirige a los sujetos de derecho internacional en general, se encuentra en la costumbre internacional y en las normas de jus cogens con obligaciones erga omnes. Dentro de la primera se cuentan diversas normas de derechos humanos, como la prohibición de la tortura y la esclavitud; la privación arbitraria de la vida o de la libertad; el reconocimiento de la personalidad jurídica del hombre y el derecho a un juicio justo ${ }^{80}$. Las segundas comprenden las normas que protegen contra el genocidio, los crímenes de guerra y los crímenes contra la humanidad. Asimismo, es posible vincular a los miembros de las Naciones Unidas a los Pactos Internacionales de derechos humanos cuando ejercen autoridad soberana directa sobre individuos en sus tareas de consolidación de la paz; ello gracias a una interpretación extensiva del Art. 2 (1) del Pacto Internacional sobre derechos civiles y políticos. Según esta interpretación, los Estados no solo están obligados al Pacto cuando sus órganos ejercen poderes soberanos en su territorio sino también fuera de él ${ }^{81}$. Siendo así que la normatividad internacional de derechos humanos

\footnotetext{
80 Wollenberg, S., (2007), p. 220.

81 Schaller, Ch., (2006), p. 29, quien se basa en las opiniones del Comité de Derechos Humanos seguidas por la Opinión Consultiva de la Corte Internacional de Justicia sobre "Legal Consecuences of the Construction of the Wall in the Occupied Paletinian Territory», I.C.J. Reports 2004, p. 136, párr. 107 ss.
} 
obliga también a las Naciones Unidas, todas las decisiones y actuaciones del Consejo de Seguridad bajo el cap. VII, incluyendo las realizadas de acuerdo con su prerrogativa de los poderes implícitos, deberán estar sujetas o acordes a los derechos humanos, las normas humanitarias y las normas de jus cogens, incluyendo el derecho de autodeterminación de los pueblos. Su cabal observancia no solo es conditio sine qua non de la legalidad de toda misión de consolidación de la paz sino también es esencial para la legitimidad, el apoyo y el éxito de estas misiones ${ }^{82}$. La práctica de administración directa de las Naciones Unidas cuenta lamentablemente con un buen historial de violaciones de los derechos humanos ${ }^{83}$, debido principalmente al descuido completo en crear y desarrollar normas y mecanismos de control y supervisión del actuar de las organizaciones internacionales. Un paso positivo que subsana en parte esta deficiencia normativa está en el trabajo codificatorio de la Comisión de Derecho Internacional

Schaller, Ch., (2006), p. 30.

83 Aunque la sujeción al derecho internacional y a los derechos humanos es reconocida por las Naciones Unidas, vid UN Doc. A/59/2005 (21.03.2005), párr. 113, se han cometido flagrantes violaciones de los derechos humanos en sus diversas misiones de consolidación de la paz. Solo basta señalar dos ejemplos: en Kosovo con UNMIK, vid. Abraham, E. (2003), accesible en: $<$ http://www.wcl.american.edu/journal/ lawrev/ 52 / abraham.pdf? rd $=1>$ (2.11.2008); y en Timor Oriental con UNTAET, vid. Beauvais, J. También vid. Devereux, A., (2009). sobre la responsabilidad internacional de las organizaciones internacionales ${ }^{84}$.

\section{La democracia}

De acuerdo con la visión política de las Naciones Unidas, la realización del Estado de derecho y los derechos humanos solo están garantizados en un orden político democrático. Es así que el establecimiento de la democracia, llamada también «democratización» (democracy-building) viene a ser el tercer imperativo esencial para la consolidación de la paz. A la vez que la solución frente a la ineficiente o carente estatalidad de los Estados que salen de un conflicto. Esta idea viene acompañada de un incremento dramático en la importancia de la democracia en la política internacional de los últimos veinte años, como se aprecia en las innumerables documentos y compromisos políticos a nivel universal (Naciones Unidas), regional y bilateral ${ }^{85}$.

84 Vid. informe de la Comisión de Derecho Internacional en su $61^{\circ}$ periódo de sesiones, 2009, un Doc A/64/10.

85 Basta mencionar el informe «Un programa de democratización» del ex-Secretario General Boutros Boutros-Ghali (UN Doc A/51/761, 1996), la Declaración del Milenio (UN Doc. A/RES/55/2, 2000); el Documento Final Cumbre Mundial 2005 (UN Doc. A/RES/60/1, párr. 136). A nivel regional es aún más patente el compromiso de los Estados con la democracia, apreciable en documentos en el marco del Consejo de Europa, la OEA, la UA, y en formaciones políticas informales como la "comunidad de democracias». 
Mientras que la base política de la democracia ha sido esencial en las relaciones internacionales, no se puede decir lo mismo respecto del derecho internacional. $\mathrm{Al}$ igual que el concepto de Estado de derecho, el de la democracia es problemático en su carácter de norma internacional y en su contenido, hechos que dificultan su materialización en el derecho internacional. No existe una obligación iusinternacional de los Estados de instaurar la democracia en sus países ni de seguir un orden democrático determinado; solo existen cometidos y compromisos políticos. De la Carta tampoco se puede desprender una obligación correspondiente. Pero el mayor problema para el avance de la democracia como norma o principio en el derecho internacional es la extremada imprecisión y confusión de su concepto y la imposibilidad práctica de llegarse a un acuerdo general vinculante sobre su contenido y alcance.

Dentro del sistema de las Naciones Unidas la confusión es aún mayor: no existe un significado válido ni un modelo único de democracia, ni en el papel ni en la práctica. Mientras algunas instituciones como el Fondo Monetario Internacional, el Banco Mundial y el Programa de las Naciones Unidas para el Desarrollo se guían por criterios democráticos liberales y manejan la democratización como una «tecnología política de ingeniería de la paz» ${ }^{86}$, aplicable a países aspirantes a la ayuda internacional, otras instituciones,

86 «Political technology of peace engeneering», vid. Bhuta, (2009), p. 38ss, 51ss. como la Asamblea General se sirven de conceptos más amplios de democracia -aunque no libre de contradicciones. En su actividad de consolidación de la paz, las Naciones Unidas siguen el primer esquema de democracia que va de la mano con el concepto de «buena gobernanza ${ }^{87}$, y centran su atención en crear o reinstaurar instituciones y mecanismos de delegación del poder y de competencias. Para ello promueven y supervisan los procesos electorales, la pluralidad de partidos políticos, y el refuerzo de estructuras parlamentarias y de la sociedad civil. Esquema de democratización que, sin embargo, no está libre de controversias porque trae el sello de la «democracia liberal», que es un modelo de orden político interno occidental, expandible dentro del proceso de globalización. No sin razón, tal empresa de democratización no solo es tachada de concepto occidental promovido por Occidente sino de proyecto neocolonial ${ }^{88}$.

El derecho internacional sigue siendo neutral frente a las diferentes formas de Estado y sus correspondientes ideologías. Este carácter de neutralidad ha sido una vez más confirmado por los Estados en la Cumbre Mundial 2005. Si bien acordaron considerar la democracia como «un valor universal», también asintieron en fundamentarla

87 Entendida como el manejo transparente y responsable del gobierno. $\mathrm{Al}$ respecto vid. Críticas que la ven como una ideología de tutelaje, un nuevo patrón de civilización, Bhuta, N., op. cit., p. 54s. 
M. Cecilia AÑaños • La consolidación de la paz...

en «la voluntad libremente expresada de los pueblos de determinar su propio sistema político, económico, social y cultural y su participación plena en todos los aspectos de su vida» ${ }^{89}$ Con ello, este concepto sufre una inflexión frente al derecho de autodeterminación de los pueblos, lo que se hace más claro cuando el mismo texto en líneas más adelante dice: «[...] y reafirmamos la necesidad de respetar debidamente la soberanía y el derecho a la libre determinación.»

\section{LA CONSOLIDACIÓN DE LA PAZ} DESPUÉS DE MEDIDAS COERCITIVAS DE LA ONU O INTERVENCIÓN MILITAR UNILATERAL

Uno de los problemas menos discutidos pero de suma importancia para el derecho internacional, por estar inmersas en él cuestiones de legalidad y legitimidad, está en la decisión de las Naciones Unidas de proceder a medidas de consolidación de la paz después de haber aplicado medidas coercitivas militares o después de una intervención militar unilateral realizada por unos Estados u otras organizaciones internacionales ${ }^{90}$. En el primer caso se

89 Documento Final UN Doc. A/REs/60/1, párr.135. Noción basada en la Resolución de la Comisión de Derechos Humanos 1999/57 (27.04.1999) «Promoción del derecho a la democracia».

90 La Intervención militar unilateral es entendida aquí como la realizada por un Estado solo o conjuntamente con otros, o por una o más organizaciones internacio- trata de operaciones de establecimiento de la paz (peace enforcement action) o «acciones de pacificación» que son controvertibles ${ }^{91}$ pero reciben el amparo legal del cap. VII de la Carta. Aquí vale tener presente que tanto la «acción de pacificación» como la consolidación de la paz que le sigue son acciones distintas y requieren de su propia fundamentación legal. Entonces, su legalidad no se extiende a las tareas de reconstrucción postconflicto, las que requerirán de una nueva resolución basada en los caps. VI o VII de la Carta.

Desde la perspectiva del derecho internacional el segundo caso es más complicado. En más de una ocasión las Naciones Unidas han ordenado o autorizado medidas de consolidación de la paz después de intervenciones militares unilaterales -no cubiertas por el cap. VII de la Carta- como en Kosovo, Afganistán e Irak. Por ser también la intervención militar unilateral y la consolidación de la paz acciones distintas, cada una de ellas requiere de su propia fundamentación legal. De ello se sigue que cualquier intervención militar

nales fuera del sistema de seguridad colectiva de las Naciones Unidas y sin autorización del Consejo de Seguridad.

91 Por tratarse de medidas que pretenden «sofocar» con la fuerza un conflicto armado en brote y por el hecho de controlar o manejar los procesos de conflictos internos del Estado afectado, que son de la competencia del pueblo, elevando así el peligro de su agravación con consecuencias negativas para el país afectado y para las Naciones Unidas. Baste citar aquí los efectos desastrosos de la misión UNOSOM II. Vid. Matthies, V., op. cit. (n.19), p. 31. 
unilateral, ya sea fundamentada en la legítima defensa, intervención humanitaria o «responsabilidad de proteger", no da título legal para la reconstrucción del Estado ocupado. Tampoco la acción de consolidación de la paz legitima una intervención militar dudosa o ilegal que le dio origen ${ }^{92}$. En tal caso para ser legal toda tarea de reconstrucción no cubierta por el consentimiento necesita el respaldo del capítulo $\mathrm{VII}^{93}$; mientras esto no sea así, rige la occupatio bellica y es aplicable el derecho de ocupación. Sin embargo, queda aún por resolver la cuestión de si es legal el orden postconflicto resultante de una intervención militar violatoria de la prohibición del uso de la fuerza. Para su respuesta se presentan dos argumentaciones: la tesis de la derivación y la de separación.

Según el argumento de la derivación, la legalidad del orden postconflicto deriva de la legalidad de la intervención militar que lo precedió. Entonces, la realización o autorización de medidas de consolidación de la paz después de una intervención militar sin título de intervención y seguida de ocupación, significa la confirmación de un acto ilegal del derecho internacional; siendo toda medida de consolidación de la paz también violatoria del derecho internacional. Bajo esta premisa, solo puede garantizarse la seguridad jurídica una vez establecida obligatoriamente la ilegalidad de la intervención militar por un órgano competente ${ }^{94}$, con la

92 Schaller, Ch., (2006), p. 6, 17 s.

93 Oeter, (2006), p. 45.

94 Schaller, Ch., op. cit. (n. 38), p. 15. consecuencia mínima de no tener por válido ese orden generado por la fuerza y no participar en él. Aquí entran a tallar las normas de la responsabilidad internacional de los Estados que prevén consecuencias para el acto ilícito como la terminación inmediata de la acción violatoria, la reparación consistente en restablecer el orden anterior a la violación, el no reconocimiento ni apoyo del orden creado con la violación iusinternacional por los demás Estados ${ }^{95} \mathrm{y}$, de ser el caso, la responsabilidad penal individual.

La tesis de la separación sostiene que existe una desconexión entre el orden postconflicto (ius postbellum) y el ius ad bellum, como la existente entre el ius ad bellum y el ius in bello. Entonces, las transgresiones del ius ad bellum no tienen consecuencias para el ius post bellum. Esta conclusión se apoya en el hecho de que el Consejo de Seguridad carece de prerrogativas para manifestarse sobre el ius ad bellum o determinar la legalidad de una intervención militar unilateral, limitándose tan solo a establecer situaciones amenazadoras o transgresoras de la paz. Esta tesis parece imponerse en vista de la escasez de debate sobre tales actuaciones de las Naciones Unidas, lo que deja sin resolver la cuestión de la legalidad del uso de la fuerza (ius ad bellum) y acarrea problemas de legitimidad a la organización, al no considerarse legítimo ni

95 Reglas de responsabilidad internacional referidas a actos ilícitos aprobadas por la Asamblea General, el 12 de diciembre de 2001, UN Doc. A/RES/56/83 (28.01.2002). 
M. Cecilia AÑaños • La consolidación de la paz...

reconocido este nuevo orden político postconflicto, producto de una transgresión del ius ad bellum por los grupos políticos afectados y su población.

\section{REFLEXIÓN FINAL}

La idea de la consolidación de la paz como servicio de asistencia a Estados en situaciones de postconflicto para fortalecer o rehabilitar su estatalidad -que conllevaría el ejercicio de su derecho de autodeterminación-, se ajusta en principio a los fines del mantenimiento de la paz de las Naciones Unidas. El problema legal y moral está en el empleo de los medios de interferencia e intervención que se producen a diferentes escalas hasta afectar derechos protegidos por el derecho internacional, como la soberania interna de los Estados y el derecho de autodeterminación de los pueblos.

Este problema acarrea otro más serio que va más allá de toda regulación jurídica: junto con la consolidación de la paz se «implantan» modelos políticos occidentales en los Estados receptores, operándose en estos no solo una transformación artificial que niega el proceso político de desarrollo genuino proveniente del pueblo mismo sino también una transformación dirigida de acuerdo a las visiones de los países actores. Por ello, las críticas de que la misma promueve una estrategia de dominación o está cimentando y reproduciendo relaciones de desigualdad ${ }^{96}$,

96 Construcción del Estado como acepción clásica de hegemonía e imperio, Korhonen, deben ser tomadas en serio, haciéndose necesario debatir sobre esta problemática y reflexionar sobre la utilidad de la consolidación de la paz en los países receptores y sus posibles efectos negativos a mediano y largo plazo en estos y para el orden mundial. Entre ellos se cuenta el peligro de perpetuar aumentar la dependencia estructural de los países receptores frente a los actores, y perpetuar el statu quo del actual orden político mundial jerárquico.

Urge pues debatir con mayor profundidad sobre este concepto en sí, teniendo en cuenta que, como parte de corrientes ideológicas liberales, coadyuva a transformar el derecho internacional de un derecho de coordinación y de carácter neutral, en jerárquico y valorativo, flexionable ante el orden político jerárquico existente, y con arreglo al cual la regla serían las afectaciones en la soberanía y autodeterminación de los pueblos de los llamados Estados frágiles o caídos. El derecho internacional no debe servir de «técnica hegemónica» sino de límite al poder para sobrevivir como tal.

La razón de ser de la consolidación de la paz, de mantenerse como propuesta sostenible, deberá consistir en constituir un instrumento útil y necesario de ayuda apoyo a Estados en situaciones de postconflicto, de acuerdo con las necesidades claramente formuladas por ese mismo Estado y su población, con pleno respeto del derecho internacional

O., op. cit. (n. 9), p. 35, 36. Construcción del Estado como medio de reinsertar estructuras de desigualdad y dominación, Bhuta, N., (2009), p. 62. 
positivo en los medios a elegir, pues solo una acción conforme con el derecho internacional puede brindar legitimidad y aceptación moral y política a proyectos concretos de consolidación de la paz ${ }^{97}$. Solo así esta seguirá siendo una tarea deseada que una gran mayoría de Estados estarán dispuestos a apoyar a largo plazo.

\section{Bibliografía}

Abraham, E.(2003), "The Sins of the Savior: Holding the United Nations Accountable to International Human Rights Standards for Executive Order Detentions in its Mission in Kosovo", American University Law Review, Vol. 52, 1291-1337.

Anghie, A. (2006), «The Evolution of International Law, Colonial and Postcolonial Realities», Third World Quaterly 27, 739753.

AÑaños Meza, M. C. (2009), La «Responsabilidad de Proteger» en Naciones Unidas y la Doctrina de la «Responsabilidad de Proteger» UNISCI Discussion Papers, $\mathrm{N}^{\mathrm{o}}$ 21 (Octubre)

BARTL, J. (1999), Die humanitäre Intervention durch den Sicherheitsrat der VN im «failed State», Frankfurt am Main, Peter Lang.

Beauvais, J. (2003), «Benevolent Despotism: A Critique of U.N. State-Building in East Timor", New York University Journal of International Law and Politics, vol. 33, 1101-1178.

Bermejo, R. y E.López-Jacoiste. (2006), «La Reforma Institucional», UNISCI Discussion Papers, N 10 Enero 23-73.

Bhuta, N. (2009), «Democratisation, statebuilding and politics as technology», en Bowden, B. y otros (Eds.), The Role of International Law in Rebuilding Societies after Conflict. Great Expectations, Cambridge, Cambridge University Press, 38-63.

97 Schaller, Ch., op. cit. (n. 38), p. 6.
Bothe, M. (1982), «Occupation, Belligerent», en Bernhardt, Rudolf (eds.), Encyclopedia of Public International Law, vol. 4, Use of Force, War and Neutrality, Peace Treaties (N-Z), North Holland, Amsterdam, 65-67. Buergenthal, Th. (1995), International Human Rights in a Nutshell, 2. Ed., St. Paul West Publishing Co.

Carrillo Salcedo, J.A. (1976), Soberanía del Estado y Derecho Internacional, Madrid Ed. Tecnos.

Chesterman, S. (2007), You, the People. The United Nations, Transitional Administration and State-Building, Oxford U.P., Nueva York.

DANChin, P. (2009), «International Law, human rights and the transformative occupation of Iraq", en Bowden, B. y otros (eds.), The Role of International Law in Rebuilding Societies after Conflict. Great Expectations, Cambridge, Cambridge University Press, 64-89.

Debiel, T. (2004), "Konfliktbearbeitung in Zeiten des Staatsverfalls: Erfahrungen und Lehren zu Beginn des 21. Jahrhunderts", en Blanke, U., (Ed.), Krisen und Konflikte. Von der Prävention zur Friedenskonsolidierung, Berlin, Berliner WissenschaftsVerlag. 21-38.

Dempsey, G. (2001), «Fool's errands: America's recent encounters with nationbuilding», Mediterranean Quarterly 12 (1), 57-80.

Devereux, A. (2009), «Selective universality? Human-rights accountability of the UN in post-conflict operations", en Bowden, B. y otros (eds.), The Role of International Law in Rebuilding Societies after Conflict. Great Expectations, Cambridge, Cambridge University Press, 198-217.

Dobbins, J. (2003), "America's Role in Nation-Building: From Germany to Iraq", Survival $\mathrm{N}^{\circ} 4,87-110$.

EpPING, V. (2007), «Völkerrechtliche Aspekte defektiver Staatlichkeit», en Epping y Hans-Joachim Volker Heintze, (eds.), Wiederherstellung staatlicher Strukturen in Nach-Konflikt-Situationen. Bochumer Schriften zur Friedenssicherung und zum 
M. Cecilia AÑaños • La consolidación de la paz...

humanitären Völkerrecht 55, Berlin, Berliner Wissenschafts-Verlag.

ETZIONi, A. (2004), «A self restraint approach to nation-building by foreign powers", International Affairs 80 (1) 1-17.

Fernández Ruiz, G. (2009), E., Estados fallidos o estados en crisis, Granada, Comares.

Fleck, D. (2003), «Humanitarian Protection Against Non-State Actors», en Frowein, J. y otros (eds.), Verhandeln für den FriedenNegotiating for Peace, Berlin, Liber Amicorum Tono Eitel, Springer, 69-94.

Funuyama, F. (2004), La construcción del Estado: hacia un nuevo orden mundial en el siglo XXI, Barcelona, Eds. B.

Gasser, H.-P. (2004), «From Military Intervention to Occupation of Territory: New Relevance of International Law of Occupation", en Fischer, H., y otros (Eds.), Krisensicherung und Humanitärer Schutz-Crisis Management and Humanitarian Protection, homenaje a Dieter Fleck, Berlin, Berliner Wissenschafts-Verlag, 139-157.

GASSER, H-P. (2008), "Recht der kriegerischen Besetzung und Menschenrechte: Leitlinien für die Konfliktlösung?», en Fischer-Lescano y otros (Eds.), Frieden in Freiheit, Baden-Baden FS für Michael Bothe, Nomos, 2008, 417-425.

Graf Vitzthum, W, (2004). (Ed.), Völkerrecht, $3^{\text {a }} \mathrm{Ed}$., Berlin, De Gruyter.

Herdegen, M. (1996), «Der Wegfall effektiver Staatsgewalt im Völkerrecht: 'The Failed State'», Thürer/Herdegen/Hohloch, Der Wegfall effektiver Staatsgewalt: The Failed State», Berichte der Deutschen Gesellschaft für Völkerrecht 34, Heidelberg C.F. Müller Verlag 49-84.

Hintze, H. J. (2007), "Völkerrechtliche Aspekte der Wiederherstellung der Rule of Law in Nachkriegsgesellschaften", Epping, V. y H.-J. Heintze (Eds.), Wiederherstellung staatlicher Strukturen in Nach-Konflikt-Situationen. Bochumer Schriften zur Friedenssicherung und zum humanitären Völkerrecht 55, Berlin, Berliner Wissenschafts-Verlag, 25-44.
Hufnagel, F.-E. (1996), un-Friedensoperationen der zweiten Generation. Vom Puffer zur Neuen Treuhand, Berlin, Duncker \& Humblot.

Krieger, H. (2000), Das Effektivitätsprinzip im Völkerrecht, Berlin, Duncker \& Humblot.

KüHNE, W. (2005), «Die Friedenseinsätze der Vereinten Nationen", Aus Politik und Zeitgeschichte, vol. 22 25-32.

Matthies, V. (1995), (Ed.), Vom Krieg zum Frieden. Kriegsbeendigung und Friedenskonsolidierung, Bremen, Ed. Temmen.

Murithi, T. (2009), The Ethics of Peacebuilding, Edinburgh Studies in World Ethics, Edinburgh EUP p. 3; Voorhoeve, J. (2007), From War to the Rule of Law: Peacebuilding after violent conflicts, Amsterdam, Amsterdam Univ. Press.

Murswiek, D. (1996), "Souveränität und humanitäre Intervention», Der Staat 35.

Oeter, S. (2005), «Post-Conflict PeacebuildingVölkerrechtliche Aspekte der Friedenskonsolidierung in Nachkriegsgesellschaften", Die Friedens-Warte 80 1-2, 41-60.

PARIs, R. (2004), At War's End. Building Peace after Civil Conflict, Cambridge, Cambridge University Press.

Pastor Palomar, A., «Soberanías fallidas y virtuales en el comienzo del nuevo milenio: Afganistán, Irak, R.D. del Congo, Sudán», (2005). en Caflish, L., y otros (Eds.), El derecho internacional: normas, hechos y valores. Liber Amicorum J. A. Pastor Ridruejo, Madrid, Servicio Publicaciones Facultad de derecho, Universidad Complutense de Madrid, 335-358, p. 337 ss.

Payandeh, M. (2005), "State-Building im Friedenssicherungssystem der Vereinten Nationen. Völkerrechtliche Rahmenbedingungen einer neuen Herausforderung für die internationale Gemeinschaft», Humanitäres Völkerrecht - informationsschriften $\mathrm{N}^{\circ} 4253-263$.

Pfarr, V. (2007), "Nation-Building in Afghanistan aus Sicht des Völkerrechts. Das Bonner Abkommen", en Epping y Heintze (Eds.), Wiederherstellung staatlicher Strukturen in Nach-Konflikt-Situationen. 
Bochumer Schriften zur Friedenssicherung und zum humanitären Völkerrecht 55 , Berlin, Berliner Wissenschafts-Verlag, 99-120.

Pozo Serrano, P. (2002), « Estados fallidos, derecho internacional humanitario y seguridad internacional, en Ramón Chornet, C. (Ed.), Los retos humanitarios del siglo XXI, Valencia, Tirant lo Blanch, 173-185.

Roberts, A. (2006), "Transformative Military Occupation: Applying the Laws of War and Human Rights", The American Journal of International Law, vol. 100, 580-622.

SCHAller, Ch. (2006), Peacebuilding und «ius post bellum». Völkerrechtliche Rahmenbedingungen der Friedenskonsolidierung nach militärischen Interventionen, Berlin, SWP-Studie.

Stahn, C. (2006), "'Jus ad bellum', 'jus in bello'... 'jus post bellum?' - Rethinking the conception of the law of armed force», European Journal of International Law, Vol. 15, No 5 921-943.

STAHN, C. (2005), "Justice and Transitional Administration: Contours and Critique of a Paradigm», en Fischer, H y N. Quénivet (eds.), Post-Conflict Reconstruction: Na-
tion-and/orState-Building, Berlin, Berliner Wissenschafts-Verlag, 141-167.

STEINER, M. (2004), «Friedenskonsolidierung: Sieben Prinzipien für Friedensmissionen», en Blanke, U., (Ed.), Krisen und Konflikte. Von der Prävention zur Friedenskonsolidierung, Berlin, Berliner WissenschaftsVerlag, 61-73.

Thürer, D. (1996), «Der Wegfall effektiver Staatsgewalt: 'The Failed State'», en Thürer/Herdegen/Hohloch, Der Wegfall effektiver Staatsgewalt: The Failed State, Berichte der Deutschen Gesellschaft für Völkerrecht 34, Heidelberg, C.F. Müller Verlag 9/45.

Voorhoeve, J. (2007), From War to the Rule of Law: Peacebuilding after violent conflicts, Amsterdam, Amsterdam Univ. Press.

Wollenberg, S. F. W. (2007), Die Regierung von Konfliktgebieten durch die Vereinten Nationen, Baden - Baden, Nomos.

Wolter, D. (2007), A UN for the 21st Century: From Reaction to Prevention. BadenBaden, Nomos.

Zwanenburg, M. (2004), "Existentialism in Iraq: Security Council Resolution 1483 and the Law of Occupation", International Review of the Red Cross $\mathrm{N}^{\circ}$ 856, 745-769. 